\title{
PATH dependency e a transformação agrária do bioma amazônico: o sentido econômico das capoeiras para o desenvolvimento sustentável
}

Francisco de Assis Costa - Professor e pesquisador do Núcleo de Altos Estudos A mazônicos (NAEA) da Universidade Federal do Pará (NAEA-UFPA)

\section{Resumo}

As capoeiras - áreas alteradas por ação antrópica que se encontram em estágios de regeneração espontânea de cobertura florestal - são componentes da paisagem rural de grande significado na Amazônia.

No último Censo Agropecuário, as áreas de capoeira perfaziam 4,5 milhões de hectares em toda a Região Norte. Uma literatura crescentemente importante considera tais áreas proxy de economias rurais decadentes e insustentáveis, sobre as quais se ergue uma pecuária de corte eficiente e sustentavel. Este artigo procura estabelecer os diferentes tipos de capoeira que se constatam na economia rural da Amazônia, associando-as às diferentes formas de produção, cujos sistemas se expressam dinamicamente como trajetórias tecnológicas concorrentes. A partir dai a) demonstra que parte dessas áreas resulta de mudanças positivas nos sistemas produtivos que produzem capoeiras com grande capacidade de regeneração - estando associada, portanto, a inovações relevantes para o desenvolvimento da Região numa perspectiva que incorpora critérios de sustentabilidade ambiental; b) demonstra que os tipos de capoeira que indicam degradação, pela baixa capacidade de regeneração, se associam à pecuária de corte, a qual na Região tem apresentado dificuldades estruturais de modernização técnica e c) indica que 0 ambiente institucional, favorecendo os sistemas que produzem capoeira degradada em detrimento daqueles que produzem capoeiras de rápida recomposiçáo, podem aprisionar (levar a um lock-in) a economia agrária da região nas piores soluções, tanto econômica, quanto social e ecologicamente.

\section{Palavras-chave}

Desenvolvimento dependente de trajetória, Amazônia, Tecnologias concorrentes.

\section{Abstract}

The "capoeiras" - altered soils by antropic action that are in expontaneous process of regeneration of its forest covering - are component of the rural landscape of great meaning in the Amazonian. In the last Agricultural Census, the areas of capoeira amounted 4,5 million hectares in the whole North Region of Brazil. A increasingly important literature considers such areas indicator of decadent and unsustainable rural economies, on which rises a pressumably efficient and sustaintainable livestock for meat production. This article tries to establish the different capoeira's types that exist in the Amazonian's rural economy, relating them to the different production forms, whose systems are dinamicaly expressed as competitive technological paths. On that base it demonstrates a) that part of those areas results of positive changes in the productive systems that produce "capoeiras" with great regeneration capacity - being associated, therefore, to important innovations for the development of the Region in a perspective that incorporates criteria of environmental sustainability; b) that the types of "capoeiras" that indicate land degradation, because of their low regeneration capacity, associate to the cut livestock, which has been presenting structural difficulties of technical modernization. The article indicates also that the prevailing institutional environment, favoring the systems that produce degraded "capoeira" in detriment of those that produce "capoeiras" of fast regeneration, can arrest (to take it into a lock-in) the agrarian economy of the Region in the worst solutions in economical, social and ecological meaning.

\section{Keywords}

Path dependency, Amazon, Concorrent technologies. 


\section{INTRODUÇÃO}

As capoeiras são um componente da paisagem rural de grande significado na Amazônia. Distinguem-se de outras formas de áreas alteradas por ação antrópica por constituírem estágios de regeneração espontânea de cobertura florestal. Na principal contabilidade do desmatamento da Amazônia, que hoje se faz por taxa de desflorestamento bruto, em que se acrescem ao "passivo ambiental", a cada ano, as áreas desmatadas em corte raso, as capoeiras, ou parte delas, seriam uma parcela de um "ativo ambiental" invisível, por serem áreas recuperadas ou em processo de recuperação ambiental, cujos valores não são levados em consideração no que seria uma taxa de desflorestamento líquido ${ }^{1}$. E tais valores são significativos. No último Censo Agropecuário, realizado em 1995, as áreas de capoeira perfaziam 4,5 milhões de hectares em toda a Região Norte: o correspondente a 8\% de toda a área apropriada naquele ano na Região, a 17\% da área com pastos naturais ou plantados, com lavouras permanentes e temporárias e com florestas plantadas, e a $14 \%$ de toda a área desmatada.

Recentemente, no bojo das tensões produzidas pela discussão ambiental e seus reflexos na Amazônia, têm sido adotadas duas perspectivas de observação das capoeiras: uma negativa, em que a capoeira importa enquanto momento de um processo de negação da floresta originária, do qual faz parte o fracasso de sua justificativa social - o uso agropecuário; outra positiva, em que a capoeira importa porque momento de recomposição das propriedades ecológicas da floresta tropical como parte de (ou após um) certo uso agropecuário da base natural. Numa visão a capoeira é expressão de um passivo, de um débito patrimonial e ecológico; noutra, ela é um ativo, uma capacidade, um patrimônio.

$\mathrm{Na}$ primeira perspectiva, as capoeiras associam-se a usos insustentáveis da base natural. Os sistemas de derruba e queima, dos quais as capoeiras fazem parte, seriam insustentáveis porque de baixa eficiência econômica, só justificáveis para (pequenos e passageiros) agentes que teriam sido expulsos para a "fronteira especulativa" em movimento na Região Amazônica pelo baixo custo de oportunidade em outras regiões. Essa é a posição de Schneider (1995, p. 15-32), completamente encampada por Margulis (2003), para quem essa "fronteira especulativa" geraria uma "fronteira consolidada",

${ }^{1}$ Os cálculos de desflorestamento são feitos pela equipe do Projeto de Estimativas de Desflorestamento da A mazônia (PRODES), do Instituto Nacional de Pesquisas Espaciais (INPE). Sobre a metodologia das estimativas, ver Krug (2001, p. 92-93). 
economicamente sustentável apenas em áreas com pluviometria intermediária, própria para a formação de uma pecuária altamente rentável e profissional. Lá onde, segue esse autor, a grande pecuária profissional não se instala em virtude da pluviometria muito elevada condição, aliás, dominante na maior parte da região - , nada sobreviveria. Nessas áreas, em virtude da elevada umidade que bloquearia a agropecuária mais eficiente, restariam, após o inexorável fracasso da shifting cultivation, terras abandonadas: capoeiras. 0 exemplo da Região Bragantina, no Nordeste Paraense, seria paradigmático. Nessa região, Margulis observa, em consonância com Chomitz e Thomas (2000) e com Schneider, em associação com os engenheiros florestais e agrônomos do Imazon (SCHNEIDER; ARIMA; VERÍSSIMO; BARRETO; SOUZA J R., 2000), "a evidência irrefutável de que muito poucas atividades econômicas são viáveis em áreas de alta pluviometria e que praticamente só a atividade madeireira pode fazer sentido" (MARGULIS, 2003, p. 65). Nesse contexto, capoeiras novas são componentes passageiros da paisagem, e capoeiras velhas são terras abandonadas, indicadores de decadência e incapacidade.

A segunda visão das capoeiras deve-se a pesquisas botânicas, biológicas e agronômicas que têm demonstrado as propriedades botânicas da capoeira - diversidade de espécies, complexidade do sistema radicular, densidade de biomassa, sendo essas propriedades tanto mais efetivas, quanto menos intenso e mais curto tenha sido o uso da área e mais tempo tenha decorrido desde a paralisação da atividade agropecuária. Daí o aumento do interesse pela valorização da capoeira, seja para o equilíbrio ambiental, quando se indica a capacidade da vegetação secundária de prestar "serviços ambientais" na manutenção da biodiversidade, no seqüestro de carbono e na manutenção do regime de chuvas, seja para a elevação da eficiência produtiva agrícola, dado seu papel na retenção dos efeitos de lixiviação e na manutenção das propriedades físicas e mecânicas do solo (PEREIRA; VIEIRA, 2001; SÁ; KATO, M.; KATO, O., 2004; VIEIRA et al., 1996; VIELHAUER; KANASHIRO; SÁ, 1997). Uma questão central que orientou vários desses estudos dizia respeito aos sistemas agrários e suas bases econômicas: 0 que se passa com a produtividade de longo prazo dos sistemas agrícolas baseados em capoeira? Após pesquisas desenvolvidas na Região Bragantina, no Nordeste Paraense, ao longo dos anos noventa, chegouse a uma resposta parcial: havia uma queda sistemática da produtividade física em função do encurtamento do tempo de corte da capoeira e da alta perda de nutrientes que o método de derruba e queima dominante na região produzia (DENICH et al., 2004; KATO et al., 1999). Assim, se 
se considerava positiva para o desenvolvimento sustentável a presença da agricultura baseada em capoeira, haveria que se buscar meios de sustar essa tendência.

Em desenvolvimento paralelo, pesquisas econômicas e sociológicas sobre a dinâmica agrária na mesma região apresentavam resultados que permitiam as seguintes assertivas:

a) no Nordeste Paraense, a tese da queda da produtividade física da shifting cultivation não se demonstrava estatisticamente numa perspectiva histórica - após a queda drástica das colheitas nos anos 30 e 40, houve uma estabilização na produtividade média da Região, de modo que as crises cíclicas que se observaram na agricultura, a partir dos anos 50, foram mais de natureza socioeconômica do que ecológica (HURTIENNE, 2001);

b) no Nordeste Paraense, verificaram-se diversos processos de intensificação da agricultura, tanto como resposta à crise das capoeiras - com seus componentes associados à produtividade física e outros associados à rentabilidade monetária e aos preços - , quanto como resultado de mudanças no ambiente institucional e nas políticas públicas de fomento agrícola (COSTA, 2000);

c) as soluções dominantes produziram inovações expressas em sistemas de produção altamente diversificados, nos quais, todavia, tenderiam a ganhar significado culturas perenes e semiperenes, como laranja, pimenta-do-reino e maracujá, em substituição à agricultura de derruba e queima (shifting cultivation), que, por suposto, perderia significado (COSTA, 1996a);

d) os sistemas resultantes apresentavam eficiência econômica e ecológica elevada, apresentando-se, pela complexidade agronômica e rentabilidade econômica, como sistemas com maior esperança de sustentabilidade (COSTA, 1996a, 1997).

Tais resultados impõem questões importantes às duas posições anteriores. À primeira, indicam que o aumento da extensão e do tempo das capoeiras pode significar a outra face de dinâmicas positivas, pode ser sinal de um processo de desenvolvimento, positivo também na perspectiva da sustentabilidade ambiental, e não de decadência.

Quanto à segunda, apontam para o fato de que as capoeiras têm duas posições em relação à shifiting cultivation: ou elas são seu produto, por serem parte constitutiva da shifiting cultivation, ou elas são o produto de sua negação. No primeiro caso, elas são internas aos sistemas de produção, com as respectivas configurações - idade, extensão e conteúdo -, resultando de decisões que importam mudanças incrementais nas 
combinações de possibilidades do estabelecimento familiar, fortemente reguladas pela disponibilidade de trabalho; no segundo caso, elas são externas aos sistemas que têm substituído a shifting cultivation, os quais prescindem dos nutrientes da sua biomassa. Assim, elas não têm idade determinada endogenamente no contexto da racionalidade produtiva: elas podem vir a ser tão velhas que se confundem com a floresta. De modo que, na perspectiva estratégica do desenvolvimento sustentável, fazer o bem implicaria a escolha nada óbvia entre o binômio "lavourascapoeira de idade limitada" e "lavouras-capoeiras de idade ilimitada". Este trabalho pretende contribuir para debater essa questão de três maneiras: a) fazendo uma discussão conceitual das diversas formas de capoeira, buscando associá-las estruturalmente à lógica econômica que as conformam; b) produzindo uma estatística dessas diversas formas de capoeiras; c) fazendo uma análise, com base em um modelo de tecnologias concorrentes, das possibilidades de evolução/negação das diversas modalidades de capoeira encontradas na Região Norte em função das diversas possibilidades tecnológicas e institucionais. Neste particular, ganham destaque as inovações mecânicas endereçadas à shifting cultivation pela introdução de técnicas de mulch (trituração da capoeira) na preparação da biomassa da capoeira para os usos agrícolas.

\section{1 - 0 LUGAR ESTRUTURAL DAS CAPOEIRAS: INDICAÇÕES TEÓRICAS}

As capoeiras formam-se em contextos econômicos dinâmicos, fortemente marcados pela heterogeneidade dos agentes, por suas formas de produção e por seus fundamentos tecnológicos. A noção de heterogeneidade que aqui se privilegiará incorpora diferenças na natureza dos agentes - especificidades moldadas nos constrangimentos estruturais de modos de produção, na tradição de Chayanov (1923) e Tepicht (1973) - e diferenças de postura associadas a "different hypotheses or beliefs or action" de agentes de mesma natureza, na perspectiva de Arthur (1994a).

Assim, considerar-se-á a dinâmica agrária da Amazônia a partir do movimento interno e das interações competitivas e cooperativas entre duas formas de produção e os agentes que as conformam: a camponesa ou familiar e a patronal. Na primeira, a estrutura básica é a unidade de produção camponesa; na segunda, encontramos estruturas com características de fazenda e outras com características de grande empresa latifundiária. 
À heterogeneidade dos agentes e seus modos de produção corresponde uma heterogeneidade tecnológica. Entender-se-á tecnologia, aqui, no sentido lato de conjunto de técnicas e procedimentos que fazem a mediação entre o trabalho humano socialmente objetivado e a natureza. Trata-se de mediação feita por aparatos tangíveis e intangíveis herdados, eles mesmos, de processos de trabalho passados, os quais constituem, por isso, "órgãos da vontade humana: o poder do conhecimento objetivado" (MARX, 1953, p. 706).

\subsection{AS CAPOEIRAS, SEUS PRODUTORES E GESTORES: A HETEROGENEIDADE DOS AGENTES}

A unidade de produção camponesa caracteriza-se por ter na família seu parâmetro decisivo: seja como definidora das necessidades reprodutivas, que estabelecem a extensão e a intensidade do uso da capacidade de trabalho de que dispõe, seja como determinante no processo de apropriação de terras nas sagas de fronteira. São camponesas aquelas famílias que, tendo acesso à terra e aos recursos naturais que ela suporta, resolvem seus problemas reprodutivos com a produção rural - extrativa, agrícola e não-agrícola -, desenvolvida de tal modo que não se diferencia o universo dos que decidem sobre a alocação do trabalho do universo dos que sobrevivem com o resultado dessa alocação. Essa unidade estrutural move-se por critérios orientados dominantemente pela eficiência reprodutiva do conjunto familiar, conforme noção já explanada antes em diversos momentos (sobretudo em CARVALHO, 2005, p. 183-194; COSTA, 1995, 2000, p. 110-130, 2002). Eficiência reprodutiva seria uma expressão formal, uma medida da eficiência da unidade camponesa enquanto microssistema orientado por uma racionalidade que procura garantir um padrão de consumo, cultural e historicamente estabelecido, com o mínimo de risco e em um nível de esforço regulado pela capacidade de trabalho da família. A eficiência reprodutiva varia diretamente com a média e inversamente com a variância da renda por unidade de trabalho familiar e com a percentagem do trabalho total necessário para a sua obtenção. Se a eficiência reprodutiva cai, a razão decisória camponesa tende a exigir mudanças: adaptativa e incremental, se a tensão é baixa e o sistema está próximo do equilíbrio (eficiência reprodutiva tende a 1); radical, se a tensão é alta e o sistema está longe do equilíbrio (eficiência reprodutiva muito baixa). Tais especificidades na forma de se reproduzir e mudar levam a uma grande diversidade nas formas como o sistema se estabelece concretamente - os diferentes estados como se apresenta mediante 
especificidades locacionais e culturais. Esses estados são os sistemas de produção, os quais refletem as disponibilidades tangíveis e intangíveis, internas e externas às unidades produtivas, destacando-se os acervos de trabalho, terra e conhecimento das famílias, no primeiro caso, e as disponibilidades infra-estruturais físicas e de conhecimento institucionalizado, bem como as formas de acesso aos bens públicos em geral, no segundo.

Na Amazônia, o que J osé Eli da Veiga tem chamado de agricultura patronal (VEIGA, 1991a, 1991b) desenvolve-se com base na empresa latifundiária e na fazenda. Ambas as estruturas dependem do assalariamento e, por isso, do mercado de trabalho, na consecução do lucro, seu objetivo primordial. Isso as torna igualmente patronais. Não obstante, as grandes empresas latifundiárias empregam exclusivamente força de trabalho assalariada e são basicamente geridas por administradores profissionais, enquanto nas fazendas a presença de trabalho e gestão familiar é recorrente. Ademais, a empresa latifundiária deriva de processo decisório que considera a propriedade rural como um item a mais de portfolio, um ativo que não se distingue, em essência, dos demais componentes da carteira que organiza a reprodução ampliada de uma parte do capital. Nesse aspecto fundamental, a empresa latifundiária pode buscar, nas suas estratégias de acumulação, uma consistência intertemporal de aplicação de ativos com horizontes mais longos de tempo que a fazenda. Esta, a sua vez, por representar geralmente toda fonte de ganho e poder do seu proprietário, resulta de processos decisórios orientados pelo curto prazo, limitados também pela capacidade informacional e cognitiva dos gestores.

\subsection{A HETEROGENEIDADE DAS CAPOEIRAS}

Capoeiras são tratos de áreas de variadas dimensões, as quais se encontram em estágios diferenciados de formação florestal em ecossistemas alterados de modo radical por ações produtivas resultantes das decisões de camponeses, de fazendeiros e das empresas latifundiárias.

Como "perceber" as capoeiras, como medi-las em todo o seu significado, isto é, no contexto econômico em que são gestadas? O Censo Agropecuário de 1995-96 traz duas categorias que, juntas, reúnem todas as terras sobre as quais se encontravam vegetações secundárias precisamente as capoeiras, tal como as definimos acima. São elas as "áreas utilizadas em descanso", que comportam todas as áreas em pousio até quatro anos, e as "áreas agricultáveis não utilizadas", que se referem 
às áreas fora de uso por mais de quatro anos. Montamos um banco de dados com base nos CD-ROM do IBGE para todos os Estados da Região Norte, cuja representação mais elementar é o estrato de área por microrregião. Nesse nível, separamos os casos dominados por estabelecimentos camponeses dos casos dominados por estabelecimentos patronais ${ }^{2}$.

A Tabela 1 apresenta os dados dessas variáveis na Região Norte, por forma de produção: se camponesa ou patronal. No total são 1,1 milhão de hectares de terras em descanso até quatro anos e 3,4 milhões de hectares de terras não trabalhadas por mais de quatro anos: os camponeses com, respectivamente, 0,7 e 1,5 milhão de hectares e as unidades de produção patronais com 0,4 e 1,9 milhão de hectares.

Tabela 1: Terras utilizadas em descanso e agricultáveis não utilizadas de acordo com o Censo Agropecuário (1995-1996).

\begin{tabular}{|l|l|l|l|l|l|l|l|l|l|}
\hline $\begin{array}{c}\text { Estado } \\
\text { ou } \\
\text { mesorregião }\end{array}$ & \multicolumn{3}{|c|}{$\begin{array}{c}\text { Terras utilizadas em descanso } \\
(\mathrm{Na})\end{array}$} & \multicolumn{2}{|c|}{$\begin{array}{c}\text { Terras úteis não utilizadas } \\
(\mathrm{Av})\end{array}$} & \multicolumn{3}{|c|}{$\begin{array}{c}\text { Total de capoeiras } \\
(\mathrm{Ac})\end{array}$} \\
\cline { 2 - 9 } & Camponês & Patronal & Total & Camponês & Patronal & Total & Camponês & Patronal & Total \\
\hline Total & 670.864 & 420.247 & 1.091 .111 & 1.457 .087 & 1.948 .096 & 3.405 .183 & 2.127 .951 & 2.368 .343 & 4.496 .294 \\
\hline
\end{tabular}

Fonte: IBGE. Censo Agropecuário: Estado do Pará, 1995-96. Tabulações especiais do autor.

\subsection{A CAPOEIRA: TEMPO E ESPAÇO}

Os problemas dessa classificação do IBGE são significativos. Estabelecendo um tempo de pousio - isto é, tempo em que, por suposto, a terra está parada por causa de sua forma de utilização - limitado a

\footnotetext{
2 Seguindo os critérios utilizados no trabalho FAO/INCRA (2000), foram considerados estabelecimentos camponeses aqueles cuja força de trabalho familiar representa no mínimo $1 / 2$ da capacidade total de trabalho. Estabelecimentos patronais são os que contratam trabalho assalariado em montante superior a essa proporção. Calculou-se a força de trabalho familiar total somando-se a categoria "Membros não-remunerados da família maiores de 14 anos" com a metade da categoria "Membros não-remunerados da família menores de 14 anos". Calculou-se a força de trabalho assalariada total dividindose a soma dos gastos com salários, empreitas e outras modalidades de contratação de força de trabalho pelo valor médio da diária prevalecente no local, no ano do censo, e multiplicando-se o resultado por 300 (dias médios de trabalho por ano). Sobre a especificidade da forma camponesa de produção, ver Costa (1995) e, sobre as expressões disso na Amazônia, ver Costa (2000).
} 
quatro anos e tratando as terras já uma vez trabalhadas, porém não aradas por tempo superior a isso, como "não utilizadas", essa classificação leva a graves erros na observação da realidade da maioria dos sistemas de produção que têm a capoeira como um de seus componentes, pois o tempo de pousio necessário aos sistemas é uma variável que depende de condições diversas. Ximenes e Van Dyle (2000, p. 50) propuseram a explicitação da relação tempo-espaço na agricultura de pousio pela relação de proporcionalidade

$$
\frac{A}{A_{a}}=\frac{t}{u}
$$

Isto é, a área total necessária ao funcionamento do sistema $(A)$ está para a área plantada $(A a)$ assim como o tempo completo de um ciclo de uso e pousio $(t)$ está para o tempo em que é possível plantar na mesma área (u). Desmembrando-se a área total do sistema em área agricultada $(A a)$ e em área de pousio $(A C)$ e o tempo total em número de anos durante os quais se pode plantar com produtividade aceitável na mesma área (u) e em número de anos de formação da capoeira $(n)$,

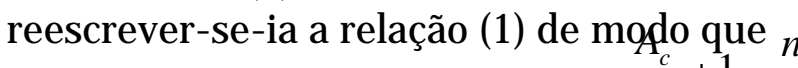

$$
\frac{A_{a}+A_{c}}{A_{a}}=\frac{u+n}{u} \backslash \quad \frac{A_{c}}{A_{a}}+1=\frac{n}{u}+1
$$

e, portanto,

$$
n=u \cdot \frac{A_{c}}{A_{a}}
$$

Se formos um pouco adiante e fizermos $A_{c}=\frac{P_{c}}{n \cdot p_{c}}$ (3) e $A_{a}=\frac{P_{a}}{u \cdot p_{a}}$

por entendermos que a área que se decide manter como capoeira é resultado de uma produção própria da capoeira - que tanto pode ser um certo volume de biomassa, como também um certo conjunto de funções, como fornecer lenha, fornecer madeira para tutorar pimentado-reino ou para a construção civil ou, simplesmente, para seqüestrar carbono - , expressa por Pc total (expressão da disponibilidade objetiva na capoeira, dos elementos que dela se requer, nos termos do sistema de produção estabelecido), obtida por uma produtividade anual por hectare $p_{c}$, e por entendermos que tal volume de biomassa ou funções é 
requerido para uma produção agrícola total $P a$, obtida a partir de uma produtividade agrícola hectare/ano de $p_{a}$, então a relação (2) seria reescrita assim:

$$
n=u\left(\frac{p_{a}}{p_{c}} \cdot \frac{P_{c}}{P_{a}}\right)^{1 / 2}
$$

Para uma mesma relação $P c / P a$ (a relação biomassa da capoeira por unidade de produto agrícola gerado com base nela é, dado um certo estado do conhecimento, relativamente constante), a idade da capoeira, isto é, o tempo necessário para que atinja o estágio de desenvolvimento que permita a realização de sua finalidade, varia diretamente com a produtividade por unidade de área da agricultura e com o aumento do tempo de plantio numa mesma área e inversamente com a produtividade da capoeira. Assim, o tempo da capoeira, $n$, como variável dependente, pode crescer ou como resultado de mudanças tecnológicas positivas na agricultura (crescimento de $p_{a}$ e aumento de $u$ ), ou como resultado de limitações na capacidade da capoeira (redução de $p_{c}$ ). Do que se depreende que parte das Terras úteis não utilizadas, do Censo, pode ter função produtiva ou derivar de trajetórias ascendentes (e não decadentes) dos sistemas agrícolas. Pergunta-se então: em que proporções isso se dá?

\subsection{A CAPOEIRA: FUNÇÃO E DISFUNÇÃO}

Dos dados da Tabela 1, deve-se reter o total - trata-se do volume total de terras que, por razões diversas, abrigam as diversas formas de capoeiras -, que denominaremos Ac. Sobre as parcelas que compõem esse total, contudo, há que discernir bem mais.

As capoeiras são produtos de três tipos de decisão dos agentes econômicos:

a) as decisões que levam à adoção de técnicas que pressupõem áreas de pousio - nesse caso, a capoeira é um componente da relação técnica de uma forma de produção, integrando, assim, um sistema de produção;

b) as que levam ao abandono de áreas cuja produtividade física média tende a zero na atividade desenvolvida, a qual tende a se repetir continuamente em outras áreas - os procedimentos tecnológicos são 
constantes, e as capoeiras, nesse caso, são produtos, não componentes dos sistemas de produção resultantes, de uma tecnologia.

c) as que levam a alterações tecnológicas, a mudanças de procedimentos a partir das quais a relação diminui pela redução absoluta do volume de terras ou, em outras palavras, as que levam à adoção de tecnologias terra-intensivas ${ }^{3}$ - nesse caso, as capoeiras são produtos de mudanças nos procedimentos tecnológicos, são resultados de inovações.

Na primeira condição, trata-se de capoeira cuja função básica é a formação de biomassa para aproveitamento na agricultura: a capoeira é, assim, meio de produção, tal qual uma máquina que produzisse nitrogênio, fósforo e outros elementos necessários à agricultura. Por isso, chamaremos a esse tipo de capoeira de capoeira-capital. 0 tempo de pousio, nessa perspectiva, é o tempo de processamento da capoeiracapital: trata-se, de um lado, de um tempo próprio da natureza, regido por leis primárias dos ecossistemas de que faz parte - o que determina, na relação (5), $p_{c}$; de outro lado, é tempo condicionado por variáveis da agricultura $\left(P_{a} / P_{c}, p_{a}\right.$ e $\left.u\right)$, resultantes do estágio do seu desenvolvimento como atividade econômica, em dado contexto que (sempre) supõe o mercado. De um modo ou de outro, trata-se de vegetação secundária com tempo determinado pela lógica do processo produtivo, para sua realização naquilo para o que foi "criada", isto é, para sua transformação em inputs do processo agrícola. Respeitado o tempo da capoeira, todavia, a extensão da capoeira-capital é, também, endogenamente contida, regulada pela extensão das necessidades da agricultura (cf. a relação 2 ), as quais, configuradas no contexto do estabelecimento camponês, obedecem aos rigores das razões reprodutivas da família.

$\mathrm{Na}$ segunda condição, a capoeira resulta do esgotamento das condições edafo-climáticas de uma dada área, por certos sistemas de produção, como resultado do impacto dos procedimentos tecnológicos a eles inerentes sobre a base natural, muito visivelmente sobre o solo. Assim, é associada a terras tratadas pelos produtores de um modo que

\footnotetext{
${ }^{3}$ Não confundir essa noção com a de "intensivas em terra" utilizada pelos economistas para designar funções de produção que usam relativamente muita terra comparativamente aos outros fatores: trabalho e capital. O que se expressa aqui é a condição de uso da terra: um sistema "intensivo em trabalho" pode usar a terra intensivamente ou extensivamente muito trabalho por unidade de área no primeiro caso e correspondentemente baixo volume de terras, por isso terra-intensivo; no segundo caso, pouco trabalho por unidade de área e correspondentemente al to volume de terras, por isso terra-extensivo (COSTA, 1996a).
} 
não difere em nada daquele do modo como a indústria trata os bens já depreciados: as sucatas. Poderíamos denominá-la, assim, de capoeirasucata ou capoeira-resíduo. Como resultado das razões que levam à existência desse tipo de capoeira, seu $p_{c}$ e seu $P a$ são muito pequenos, tendendo a zero; portanto, seu tempo, $n$, tende, na relação (5), ao infinito, independentemente das demais condições. Com o tempo tendendo ao infinito, esse tipo de capoeira teria uma extensão também tendendo ao infinito (cf. relação 2) - ela não seria, nesses termos, endogenamente contida. Por outra parte, numa perspectiva econômica, as capoeirassucata nem sempre são sintomas da decadência dos sistemas que as geraram, muito menos de seus gestores: elas podem ser uma condição para que a rentabilidade desses sistemas se mantenha, ou mesmo aumente.

$\mathrm{Na}$ terceira condição, tipicamente aquela produzida pela substituição de formas extensivas por formas mais intensivas de uso da terra - a substituição, por exemplo, da shifting cultivation ou da pecuária extensiva por plantio de culturas perenes e semiperenes - , a capoeira é o resultado da adoção de novas técnicas que tornaram a capoeira-capital economicamente obsoleta, isto é, sem função no sistema de produção, mesmo que sua capacidade física de produção de biomassa seja elevada, mesmo que ela apresente capacidade de operação. Por isso, tais capoeiras associam-se a terras no geral vistas como bens ociosos, justificáveis tão-somente como reserva de valor. Chamaremos aqui tais áreas de capoeira-reserva. Em função das condições que levam à formação da capoeira-reserva, $P a$ (a produção agrícola dependente da capoeira) na relação (5) é muito pequena e tende a zero, fazendo com que aqui também se tenha uma capoeira livre de regulação de tempo para que se transforme em elementos para a agricultura. Há, entretanto, quanto a isso, uma diferença importante em relação às capoeiras-sucata: nestas, o fato de $p_{c}$ tender a zero faz $P c$ (isto é, a expressão objetiva da maturidade da capoeira) tender a zero também, no caso extremo, a desertificação (cf. relação 3); nas capoeiras-reserva, por sua vez, as condições de formação permitem $p_{c}$ significativamente diferentes de zero, permitindo níveis de maturidade correspondentes no tempo.

Como estimar essas parcelas? Esta não é uma tarefa imediata, porque as grandezas são relacionais entre si e com os demais elementos da economia de que fazem parte. É preciso, pois, posicioná-las no contexto dos sistemas de produção, de modo que se apresentem como resultado de uma dinâmica econômica. Isso exige tratar os eventos relacionados à capoeira como problemas de alocação de recursos em contextos em que agentes produtivos de naturezas diversas interagem 
entre si e com o entorno institucional, produzindo dinâmicas de desenvolvimento complexas e fortemente dependentes de trajetórias. Disso nos ocuparemos em seguida.

\section{2 - AGENTES HETEROGÊNEOS, INSTITUIÇÕES E PROCEDIMENTOS TECNOLÓGICOS}

Como se relacionam agentes heterogêneos entre si e com seus respectivos ambientes institucionais em um processo aberto, isto é, histórico, de desenvolvimento, do qual resultam diferentes sistemas, que produzem as capoeiras dos diversos tipos acima discutidos?

Considerando que há, por algum critério, tipos de capoeiras desejáveis e tipos indesejáveis, como é possível interferir em tais processos para que a formação das primeiras seja estimulada em detrimento das outras?

\subsection{MODELO}

Arthur (1994b, p. 13-32) desenvolve um modelo que pode nos ajudar nessa matéria. A questão fundamental da heterogeneidade dos agentes é suscitada pela teoria evolucionista, na qual a decisão de um agente é influenciada pelas decisões dos outros agentes, considerados os retornos (crescentes, estacionários ou decrescentes) produzidos por externalidades. Portanto, o papel das instituições - organizações e normas - é incorporado de modo explícito na orientação dos procedimentos dos agentes. Em um contexto de rendimentos crescentes, tal fundamento leva à percepção da dinâmica econômica de um modo completamente indeterminado, em que a história tem lugar na forma da consideração endógena dos eventos passados, na forma de objetivação de ações presentes visando necessidades historicamente contextualizadas, necessidades observadas por agentes diferentes, que se relacionam de modos também diferentes com o ambiente, e na forma de possibilidades futuras em aberto. Essa perspectiva interessa-nos. Os principais destaques do modelo de Arthur são os seguintes ${ }^{4}$ :

\footnotetext{
${ }^{4}$ Licha (1996) apresentou, criativa e didaticamente, o modelo de Arthur $(1988,1994)$ com as incorporações de Heiner (1988). Muito devemos aqui aos seus esforços. O que faremos a seguir, porém, agrega nossas próprias considerações sobre várias das concepções presentes nos textos originais, sobretudo realçando aspectos particularmente importantes para o nosso problema.
} 
a) os agentes movem-se por procedimentos path-efficient, a partir dos quais, em qualquer tempo $t$, se há duas tecnologias $A$ e $B$, a escolha da tecnologia $A$, que se estabelece na variante $m$ com payoff $\mathrm{P}_{A}(m)$, enquanto a tecnologia $B$ se situa na variante $k<m$, se fará enquanto $P_{\mathrm{A}}(\mathrm{m}){ }^{3} \operatorname{Max}_{j}\left\{P_{\mathrm{B}}(j)\right\}$ para $k £ j £ m$

b) existem dois procedimentos ou tecnologias $A$ (que produz capoeirassucata, por exemplo) e B (que produz capoeiras-reserva) e um número grande (infinito!) de agentes econômicos que podem escolher entre esses dois procedimentos - esses agentes associam-se, no agrário, à condição finita dos recursos não renováveis, em particular da terra;

c) existem dois tipos de agentes, $\mathrm{R}$ (os camponeses, por exemplo) e $\mathrm{S}$ (os agentes patronais, por exemplo), com preferências diferentes, sendo o número de cada tipo de agente igual;

d) o retorno monetário, para um agente, pela adoção de um procedimento é dado pela estimação do valor presente líquido do seu resultado num horizonte temporal apropriado;

e) as expressões $n_{A}$ e $n_{B}$ representam o número de adotantes de $A$ e $B$, respectivamente, e $n=n_{A}+n_{B}$, o número total de adoções realizadas;

f) os agentes $\mathrm{R}$ e $\mathrm{S}$ conhecem o número de adoções realizadas por cada procedimento;

g) os retornos associados a A e B para cada agente, já consideradas as adoções anteriores, correspondem aos valores demonstrados na seguinte tabela de payoffs:

\begin{tabular}{|c|c|c|}
\hline $\begin{array}{l}\text { Agente } \quad \backslash \\
\text { Ação }\end{array}$ & A & B \\
\hline $\mathrm{R}$ & 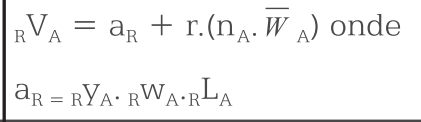 & $\begin{array}{l}{ }_{R} V_{B}=b_{R}+r \cdot\left(n_{B} \cdot \bar{W}_{B}\right) \text { onde } \\
b_{R}={ }_{R} Y_{B} \cdot{ }_{R} W_{B} \cdot{ }_{R} L_{B}\end{array}$ \\
\hline S & $\begin{array}{l}{ }_{\mathrm{S}} \mathrm{V}_{\mathrm{A}}=\mathrm{a}_{\mathrm{S}}+\mathrm{s} \cdot\left(\mathrm{n}_{\mathrm{A}} \cdot \bar{W}_{\mathrm{A}}\right) \text { onde } \\
\mathrm{a}_{\mathrm{S}}=\mathrm{s} \mathrm{Y}_{\mathrm{A}} \cdot{ }_{\mathrm{s}} \mathrm{W}_{\mathrm{A} \cdot \mathrm{R}} \mathrm{L}_{\mathrm{A}}\end{array}$ & $\begin{array}{l}{ }_{\mathrm{s}} \mathrm{V}_{\mathrm{B}}=\mathrm{b}_{\mathrm{S}}+\mathrm{s} \cdot\left(\mathrm{n}_{\mathrm{B}} \cdot \bar{W}_{\mathrm{B}}\right) \text { onde } \\
\mathrm{b}_{\mathrm{S}}=\mathrm{s} \mathrm{Y}_{\mathrm{B}} \cdot \mathrm{s}_{\mathrm{s}} \mathrm{W}_{\mathrm{B}} \cdot{ }_{\mathrm{R}} \mathrm{L}_{\mathrm{B}}\end{array}$ \\
\hline
\end{tabular}

onde:

a) $a_{R}$ e $b_{R}$ são as parcelas do payoff derivadas estritamente dos procedimentos tecnológicos, nos quais, ${ }_{R} \mathrm{y}_{A} e_{R} \mathrm{~V}_{B}$ são os retornos por unidade de área $e_{R} w_{A} e_{R} y_{B}$ são as relações terra/trabalho aplicadas pelos agentes de tipo $R$ nos montantes de trabalho ${ }_{R} L_{A} e_{R} L_{B}$, conforme as ações-tecnologias-procedimentos $A$ ou $B$, respectivamente; 
b) $a_{R}>b_{R}$ sendo a diferença da medida da preferência de $R$ por $A$ (preferência não natural, mas condicionada por diferenças na disponibilidade de terras);

c) $a_{s}$ e $b_{s}$ são as parcelas do payoff derivadas estritamente dos procedimentos tecnológicos, no quais ${ }_{S} \mathrm{y}_{A} e_{S} \mathrm{y}_{B}$ são os retornos por unidade de área provenientes da aplicação pelos agentes de tipo $S$ dos montantes de trabalho ${ }_{S} \mathrm{~L}_{A}$ e ${ }_{S} \mathrm{~L}_{B}$ nas condições técnicas que permitem as relações terra/trabalho ${ }_{S} \mathrm{~W}_{\mathrm{A}}$ e $\mathrm{W}_{\mathrm{B}}$, próprias das açõestecnologias-procedimentos $A$ ou $B$, respectivamente;

d) $a_{S}<b_{S}$ sendo a diferença da medida da preferência de $S$ por $B$;

e) com $r>0$ e $s>0$, caracterizar-se-ia um ambiente de retornos crescentes para ambos os procedimentos - o que refletiria as condições em que os ganhos derivados dos efeitos de aglomeração que a expansão de um procedimento produz, somados aos ganhos que os aperfeiçoamentos institucionais e organizacionais (ou, simplesmente, o incremento da capacidade de definição dessas instituições e organizações) resultantes dessa expansão superam o incremento dos custos globais da pressão sobre os fatores daí derivados - assim, com $r=0$ e $s=0$ ter-se-ia um ambiente de retornos constantes e com $r<0$ e $s<0$, um ambiente de retornos decrescentes.

a) Seja:

$\mathrm{x}_{\mathrm{A}}=\mathrm{n}_{\mathrm{A}} \cdot \bar{W}_{\mathrm{A}} /\left(\mathrm{n}_{\mathrm{A}} \cdot \bar{W}_{\mathrm{A}}+\mathrm{n}_{\mathrm{B}} \cdot \bar{W}_{\mathrm{B}}\right)$ a participação da Ação A no total das disponibilidades de recursos não renováveis $\left(\bar{W}_{A}\right.$ a disponibilidade média, $\mathrm{n}_{\mathrm{A}} \cdot \bar{W}_{\mathrm{A}}$ o total apropriado de terras pelos que adotam a tecnologia $\mathrm{A} ; \bar{W}_{\mathrm{B}}$ a disponibilidade média, $\mathrm{n}_{\mathrm{B}} \cdot \bar{W}_{\mathrm{B}} \mathrm{O}$ total apropriado de terras dos que adotam a tecnologia $B$ ) e $d n=n_{A} \cdot \bar{W}_{A}-n_{B} \cdot \bar{W}_{B} 0$ valor da diferença entre as disponibilidades de terras orientadas (ou passível de orientação) para as diferentes adoções. Considerando que a seqüência dos dois tipos de agentes é desconhecida dn segue um passeio aleatório de modo que, na $n$-ésima escolha, $x_{A}=0,5+d n / 2 W$, em que $W$ é o total de terras apropriadas por todos os atores. 


\subsection{A DINÂMICA: TECNOLOGIAS EM COMPETIÇÃO E OS RISCOS DE LOCK-IN, DE APRISIONAMENTO EM SOLUÇÕES ÚNICAS, NÃO NECESSARIAMENTE AS MELHORES}

Especificado o modelo, renovemos a pergunta inicial: considerando que os agentes $\mathrm{R}$ e $\mathrm{S}$, não obstante suas preferências iniciais, podem escolher livremente entre as ações/procedimentos/tecnologias A e B, como será a estrutura final a longo prazo? Será dominada por A (os procedimentos que garantem a expansão das capoeiras-sucata) ou por $B$ (aqueles que garantem as capoeiras-reserva)? Será dividida entre as duas? Em que proporções?

Para responder a essas questões, é necessário esclarecer em que condições os agentes mudam. Uma primeira resposta é: os agentes de tipo R, por exemplo, estarão dispostos a mudar sua preferência de $A$ para $B$ se a adoção de $B$ resulta em payofffinal, tal que ${ }_{R} V_{B}>{ }_{R} V_{A}$. Tomando os valores de ${ }_{R} V_{A}$ e de ${ }_{R} V_{B}$ explicitados na tabela de payoffs acima, isso implica a existência de um valor $d_{n}$, isto é, a diferença entre o número dos que adotam $A$ e o número dos que adotam $B$, a partir da qual se adotará sistematicamente a tecnologia $B$. Tal condição se explicita se

$$
\mathrm{d}_{\mathrm{n}}<\frac{\left(\mathrm{b}_{\mathrm{R}}-\mathrm{a}_{\mathrm{R}}\right)}{\mathrm{r}}
$$

Por razões equivalentes, os agentes de tipo $S$ mudam sua escolha de B para A sistematicamente se

$$
\mathrm{d}_{\mathrm{n}}>\frac{\left(\mathrm{b}_{\mathrm{S}}-\mathrm{a}_{\mathrm{S}}\right)}{\mathrm{s}}
$$

Há, digamos, duas barreiras representadas pelas proporções de agentes que adotam as tecnologias (procedimentos) em disputa: aquela em que começa a desigualdade descrita em (7) e aquela em que começa a desigualdade descrita em (8). Chamemos esses valores de $D_{B}$ e $D_{A}$, respectivamente. Distinguem-se, a partir daí, três regiões em um plano $(d n, n)$ que representamos na Figura 1: há a região II que se situa abaixo de $D_{B}$ e compreende os pontos da desigualdade (7), a região III que se situa acima de $D_{A}$ e compreende os pontos da desigualdade (8) e há ainda o campo I que fica entre $D_{A}$ e $D_{B}$. Para as regiões II e III, os valores 
$D_{A}$ e $D_{B}$ funcionam como barreiras de absorção; no campo I, eles funcionam como barreiras de reflexão de $d_{n}$.

Se r e s são negativos ou nulos, isto é, se prevalecem rendimentos constantes ou decrescentes, então $d_{n}$ vagueará pela região I, sem jamais ultrapassar as barreiras $D_{B}$ e $D_{A}$. Em tal contexto, considerando a pressuposição enunciada no item 13, é possível responder à questão proposta: a estrutura de longo prazo seria caracterizada por uma divisão na qual a produção será repartida à base de $50 \%$ para cada tecnologia (ARTHUR, 1994b, p. 22). Nesse caso, em que prevalecem os pressupostos básicos da teoria neoclássica, haveria flexibilidade, de modo que intervenções de política econômica poderiam corrigir eventuais distorções pela movimentação das barreiras, possível pela intervenção em r e s. Qualquer movimentação, nesse caso, implicaria a adoção dos parâmetros decisórios que podem afetar as escolhas. Aqui, como a ergodicidade pressuposta garante a path-efficience dos processos, também se tornaria fácil demonstrar que venceria a tecnologia mais eficiente ou elas compartimentam a estrutura em condições tais que seus resultados se igualam.

Em ambientes de rendimentos crescentes, entretanto, $r$ e $s$ são positivos, e o $d_{n}$ romperá uma das barreiras com probabilidade 1 (ARTHUR, 1994b, p. 22), de modo que prevalecerá, ao final, ou o procedimento/tecnologia $A$, ou o procedimento/tecnologia $B$ - a participação de $A$ será necessariamente 1 ou 0 quando $B$ for 0 ou 1. À questão proposta poder-se-ia responder, naturalmente, que a dominância de $A$ ou de $B$ seria 0 ou 1. Porém, em qualquer dos casos se estaria errando com a probabilidade de 1/2. A rigor, o processo é indeterminado porque, por ser não-ergódico e dependente de trajetória, depende dos (porque não esquece os) eventos históricos e condições iniciais. Como resultado, tem-se a possibilidade de aprisionamento, lockin, do sistema em situações (nas regiões II e III) em que se perde a flexibilidade de ajustamento, tanto mais quanto mais o sistema tenha se afastado das barreiras $D_{B}$ ou $D_{A}$. Em tais situações, perde-se a flexibilidade de ajustamento porque as necessidades de incremento de r e s para a reposição dos parâmetros em nível capaz de influenciar as decisões crescem sem limites. Ademais, em um contexto de rendimentos crescentes, a eficiência de trajetória não é garantida. Isto é: o sistema pode tornar-se dominado pela tecnologia menos eficiente. Nesse tipo 
de situação, se o sistema estivesse aprisionado na região III, onde prevalece exclusivamente $A$, os agentes $R$ não sofreriam perdas - os agentes $S$, entretanto, teriam uma perda, uma vez que teriam tido um ganho $\left(b_{s}-a_{s}\right)$ se sua tecnologia preferencial tivesse sido igualmente desenvolvida e colocada à escolha:

Em resumo, uma corrida de agentes de um certo tipo, os quais preferem inicialmente a opção de desenvolvimento mais lento, pode aprisionar o mercado nessa opção inferior, enquanto igual desenvolvimento da tecnologia excluída no longo prazo teria remunerado melhor ambos os agentes (ARTHUR, 1994b, p. 24).

\subsection{LOCK-IN E POLÍTICA: COMO É POSSÍVEL INTERFERIR PREVENTIVAMENTE NA REALIDADE?}

Sendo $r$ e s positivos, quer dizer, se se está em um contexto de rendimentos crescentes, então o aumento de r implica o deslocamento da barreira $D b$ na direção do centro do sistema, antecipando o momento a partir do qual o sistema entra em lock-in em relação a $B$, para $D b^{*}$ na Figura 1. De modo similar, se $s$ cresce, a barreira $D a$ desloca-se para $D a$, antecipando a barreira a partir da qual o sistema entra em lock-in em relação a $A$.

Considere-se, agora, que, seguindo um certo critério de avaliação de eficiência, se estabeleça que um dos procedimentos, digamos o $B$, seja, em uma perspectiva transcendente aos agentes, em uma perspectiva social, pois, melhor que o outro. 0 que se deveria fazer, considerando as possibilidades indicadas de desenvolvimento endógeno e rendimentos crescentes, para que $B$ prevaleça sobre seu concorrente? $\mathrm{O}$ que poderia fazer a política pública em geral? 0 que poderia fazer a Ciência e Tecnologia (C\&T)? 


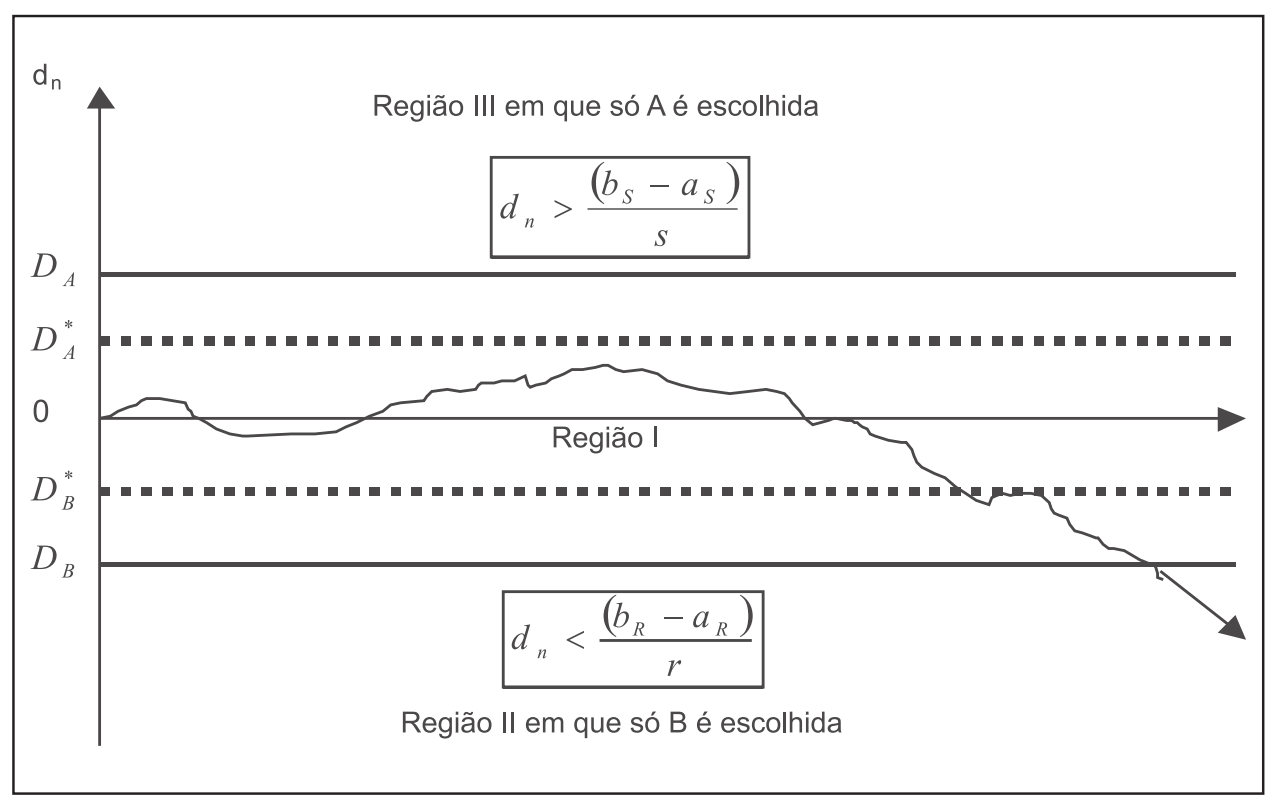

Figura 1: Diferenças na adoção de procedimentos em competição: trajeto aleatório com barreiras de absorção em movimento em função de $r$ es.

Para todos os casos, a resposta é imediata: colocar a barreira de absorção do procedimento $B$ (Bom!) o mais próximo possível do centro do sistema e afastar a barreira de absorção do procedimento $A$, seu concorrente, o máximo possível do centro do sistema. A prevenção é a chave, pois, se o procedimento indesejável entrar em lock-in, o sistema, como se viu, perde flexibilidade, tornando-se fechado à reorientação - o que quer dizer que, ou ele vai às últimas conseqüências da ineficiência incorporada no procedimento dominante, ou custa muito caro redirecioná-lo por vontade política. Isso implica três tipos de providências: as que elevam as vantagens ou reduzem as desvantagens iniciais da tecnologia $B$ em relação a sua concorrente - no modelo, as que reduzem a diferença entre os retornos diretamente associados às tecnologias, a qual justifica a preferência inicial do agente de um certo tipo (as que reduzem a diferença $b_{R}-a_{R}$ às vistas do agente $R$ ); as que elevam a eficiência do ambiente no que se refere a $B$ e reduzem a eficiência de seu concorrente - no modelo, as que elevam $r$ e reduzem $s$. 


\section{3 - AS DIVERSAS FORMAS DE CAPOEIRA COMO EXPRESSÃO DE DINÂMICAS COMPETITIVAS ENTRE PROCEDIMENTOS TECNOLÓGICOS}

Há dois grandes grupos de agentes na Amazônia, os camponeses e os agentes patronais, gerindo sistemas de produção que evoluem adotando dois tipos alternativos de procedimentos tecnológicos: os que formam capoeiras-reserva e os que formam capoeiras-sucata. Formam capoeiras-reserva os procedimentos que substituem os sistemas de produção terra-extensivos, os quais podem pressupor ou não capoeiracapital, por sistemas terra-intensivos. A implantação e o desenvolvimento de atividades que usam a terra mais intensivamente pela aplicação de mais trabalho e capital por unidade de área levam à redução da extensão total das terras, se a estrutura produtiva tiver limites de força de trabalho e capital. 0 limite da força de trabalho é endógeno e estrutural, no caso da agricultura camponesa. Por se fundar no trabalho familiar, só recorrendo ao trabalho assalariado como último recurso em uma seqüência de possibilidades (COSTA, 1996a, 2002), a restrição da força de trabalho é, nessa forma de produção, estrutural, e a adoção de uma técnica que exige mais trabalho por unidade de área induzirá uma redução na área total trabalhada. Mas esse também poderá ser o caso de sistemas patronais de produção, a depender da extensão e da qualidade do mercado de trabalho. Nesse caso, trata-se de um limite exógeno às unidades produtivas - tanto mais efetivo, porém, quanto mais ampla e forte a agricultura camponesa.

A produção familiar rural (digamos, agentes de tipo R, no modelo de Arthur) apresenta dois grandes grupos de procedimentos: os que configuram a shifting cultivation e suas variantes com componentes de importância variada da pecuária bovina e os que organizam sistemas que intensificam o uso da terra, principalmente pelo plantio de culturas permanentes. A reprodução da shifting cultivation leva à formação de capoeiras-sucata (digamos, procedimentos de tipo A). A montagem de sistemas com base em culturas permanentes gera capoeiras-reserva (procedimentos do tipo B).

A produção patronal (agentes de tipo S) apresenta também dois grandes grupos de procedimentos: os que fazem a pecuária de corte extensiva e especializada e os que levam à pecuária de corte intensiva com combinações variadas de outras atividades. A reprodução da pecuária de corte extensiva leva à formação de capoeiras-sucata (procedimentos de tipo A). A intensificação da pecuária pode gerar capoeiras-reserva (procedimentos do tipo B). 
Consideradas essas premissas, façamos duas coisas: a) vejamos como as diversas capoeiras compunham o total de capoeira que o Censo apresentou e b) vejamos como elas têm evoluído no tempo.

\subsection{OS DIVERSOS TIPOS DE CAPOEIRAS NO CENSO}

Comecemos pelas capoeiras-reserva. Há as que provêm da passagem de sistemas agrícolas extensivos para sistemas agrícolas intensivos e as que provêm da passagem de sistemas pecuários extensivos para intensivos. Para as primeiras, considere-se que áreas com culturas temporárias ou pastos em um montante $A$ convertam-se em áreas com culturas permanentes em um montante $A_{a}^{p}$ e em capoeiras, em um montante $A_{c}{ }^{R}$, de modo que

$$
A=A_{c}^{R}+A_{a}^{P}
$$

Considerando-se o modelo de Arthur para um único agente em um contexto de rendimentos constantes (rendimentos provenientes do ambiente institucional iguais a zero), a conversão se fará enquanto

$$
A \bullet p £ A_{a}^{P} \bullet p_{a}^{P}+A_{c}^{R} \bullet p_{c}^{r}
$$$$
\frac{A_{c}^{R}}{A_{a}^{P}}+1=\frac{p_{a}^{P}}{p}
$$

Isto é, a área total aplicada no uso anterior multiplicado pela rentabilidade desse uso por unidade de área $(p=$ proxy do payoff da shifting cultivation) é menor ou igual à área aplicada com permanentes, multiplicada pela rentabilidade das permanentes por unidade de área ( $p_{a}^{p}=$ proxy do payoff dos sistemas com culturas permanentes) mais a área com capoeira multiplicada pela rentabilidade da capoeira $\left(p_{c}^{r}\right)$. Se substituirmos $A$ em (10) pelo seu valor em (9), se considerarmos adicionalmente que o valor produzido pela capoeira é irrelevante (momentaneamente), portanto $p_{c}^{r}=0$, e que o processo de conversão se faz até seu limite, em que os dois termos da inequação se igualam, então:

$$
\frac{A_{c}^{R}+A_{a}^{P}}{A_{a}^{P}}=\frac{p_{a}^{P}}{p} \quad \backslash \quad \text { e, assim, }
$$




$$
A_{c}^{R}=\left(\frac{p_{a}^{P}}{p}-1\right) \bullet A_{a}^{P}
$$

Há valores para todas essas variáveis no Censo Agropecuário, de modo que podemos encontrar a área das capoeiras-reserva para cada caso do nosso banco de dados (ver 1.2). Não é possível, contudo, distinguir a área com pecuária intensiva da área com pecuária extensiva. Não podemos, portanto, especificar a relação (9) e, portanto, não sabemos quanto das capoeiras-reserva provém da intensificação da pecuária.

As capoeiras-sucata $\left(\mathrm{A}_{c}{ }^{\mathrm{s}}\right)$ têm dois componentes: o que deriva da pecuária bovina e o que deriva da shifting cultivation. As capoeirassucata que provêm da pecuária são determinadas pela proporção do solo exigida pela pecuária no conjunto das atividades que produzem capoeira (pecuária e culturas temporárias). Essa proporção projeta-se sobre a área com capoeira que não é explicada pela formação de capoeiras-reserva. Assim,

$$
A_{c}^{S}=\left(\frac{A_{a}^{\text {Pec }}}{A_{a}^{\text {Pec }}+A_{a}^{\text {Temp }}}\right) \bullet\left(A_{C}-A_{C}^{R}\right)
$$

Com os dados do Censo podemos facilmente calcular, caso a caso, tais áreas. Mas não temos como calcular, agora, a capoeira-sucata provinda da shifting cultivation.

Finalmente, as capoeiras-capital $\left(A_{c}{ }^{K}\right)$ seriam

$$
A_{c}^{K}=A_{C}-A_{C}^{R}-A_{C}^{S}
$$

A plicadas essas relações aos dados do Censo Agropecuário, obtêmse os resultados apresentados na Tabela 2 para a Região Norte. 
Tabela 2: As diversas formas de capoeira no Estado do Pará (1995-1996) (ha).

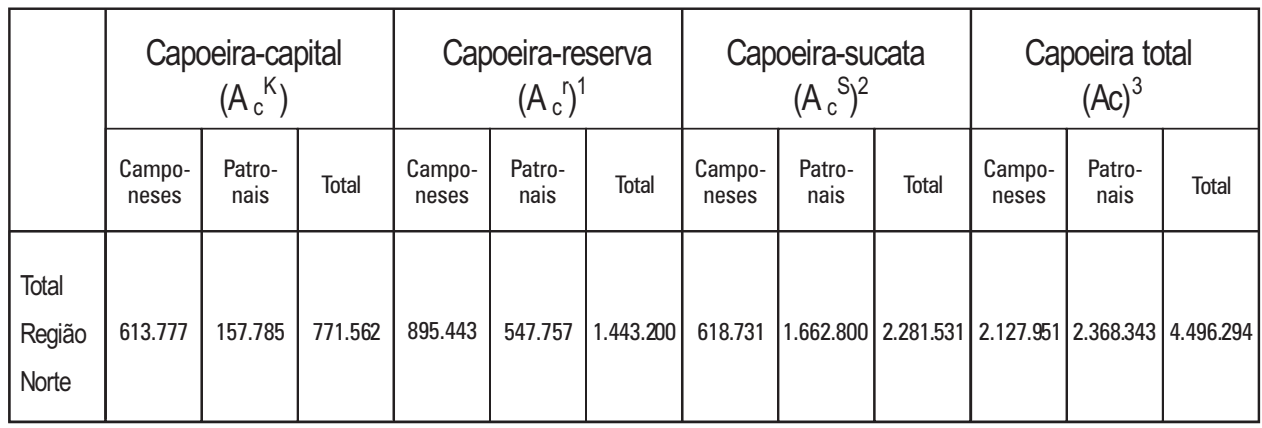

Fonte: IBGE. Censo Agropecuário: Estado do Pará, 1995-96. Tabulações especiais do autor.

\section{Notas:}

${ }^{1}$ A plicação da relação (11) com as seguintes restrições: a) se $A_{c}{ }^{r}>A c$, então $A_{c}{ }^{r}=A c$; b) se $A_{c}{ }^{r}<0$, então $\left.A_{c}{ }^{r}=0 ; c\right)$ considerando $p$ como sendo $a$ renda líquida total por unidade de área destinada à pecuária e às culturas temporárias, incluindo nessa área as capoeiras necessárias para um pousio de 6 anos e a utilização de um plantio de culturas brancas na mesma área por 2 anos.

${ }^{2}$ A plicação da relação (12) com a seguinte restrição: se $A_{c}{ }^{5}>A c-A_{c}{ }^{r}$, então $A_{c}{ }^{S}=A c-A_{c}{ }^{r}$.

${ }^{3}$ A plicação das relações (13).

As terras em forma de capoeira-reserva montaram a 1,4 milhão de hectares, 0,9 milhão dos camponeses ( $64 \%$ do total) e o resto, dos estabelecimentos patronais.

As terras abandonadas, que aqui tratamos como capoeira-sucata ou capoeira-resíduo, seriam equivalentes a 2,3 milhões de hectares, dos quais 30\% associados aos sistemas de produção camponeses e $70 \%$ aos sistemas de produção patronais.

As capoeiras-capital, as que se constituem em componentes ativos dos sistemas de produção, perfazem um total de 771.562 ha, $80 \%$ dos quais são dos camponeses e $20 \%$, dos patronais. 


\section{4 - FORMAÇÃO DE CAPOEIRAS-RESERVA PELA EXPANSÃO DAS CULTURAS PERMANENTES DESDE O ANO DO CENSO}

Segundo o modelo de Arthur, os sistemas de produção com base em culturas permanentes geram capoeiras-reserva, desde que seus payoffs superem os de seus concorrentes, que geram capoeira-sucata. Isso se dá na medida em que reduzem a diferença entre os retornos diretamente associados às tecnologias, a qual justifica a preferência inicial do agente de um certo tipo (as que reduzem a diferença $b_{R}-a_{R}$ às vistas do agente $R$ ) e/ou que elevam a eficiência do ambiente institucional e infra-estrutural no que se refere a $B$ e reduzem a eficiência de seu concorrente - as que elevam $r$ e reduzem $s$.

Usaremos como proxy da rentabilidade líquida dos sistemas baseados em culturas permanentes a rentabilidade do trabalho - a qual é diretamente influenciada pela produtividade monetária da terra e pela relação terra/trabalho prevalecente. A produtividade monetária, por seu turno, depende da produtividade física e dos preços dos produtos envolvidos, de modo que a relação produtividade monetária/ produtividade física expressa a oscilação dos preços.

No ano do Censo, 1995, a produtividade monetária da terra das culturas permanentes era superior à das culturas temporárias para 11 das 19 mesorregiões da grande Região Norte (ver Gráfico 1 e notas). Na média do conjunto, contudo, o índice que expressa a relação era relativamente baixo, 1,2 .

0 ano do Censo constituiu um ponto intermediário numa trajetória de elevação do diferencial de produtividade monetária em favor das culturas permanentes, já iniciada antes, em 1990, tendência que se mantém claramente até 1997. A partir daí, a relação entre as produtividades monetárias dos dois grupos de culturas estabiliza-se, com tendência de queda no final do período. Os diferenciais de produtividade física comandaram as oscilações e tendências até a última fase do período. A partir de 2000, enquanto o diferencial da produtividade monetária tende a cair, o da produtividade física cresce configurando um momento particularmente decidido pelos preços (cf. Gráfico 2).

O que se passa no último período na determinação dos diferenciais de produtividade monetária (proxy do payoff), entre as culturas permanentes e as temporárias da shifting cultivation, explicita de modo particularmente claro a intervenção de aspectos institucionais.

Em primeiro lugar, porque os esforços de pesquisa provindos de institutos e universidades governamentais ou não governamentais têm 
influenciado decisiva e positivamente a produtividade física. A política de crédito tem influído na difusão dos resultados desses esforços ${ }^{5}$. Sobre isso, mencionem-se as mudanças institucionais iniciadas com o Fundo Constitucional de Financiamento do Norte (FNO) (COSTA, 2005), que se projetaram sobre todo o ambiente institucional de pesquisa e extensão agropecuária.

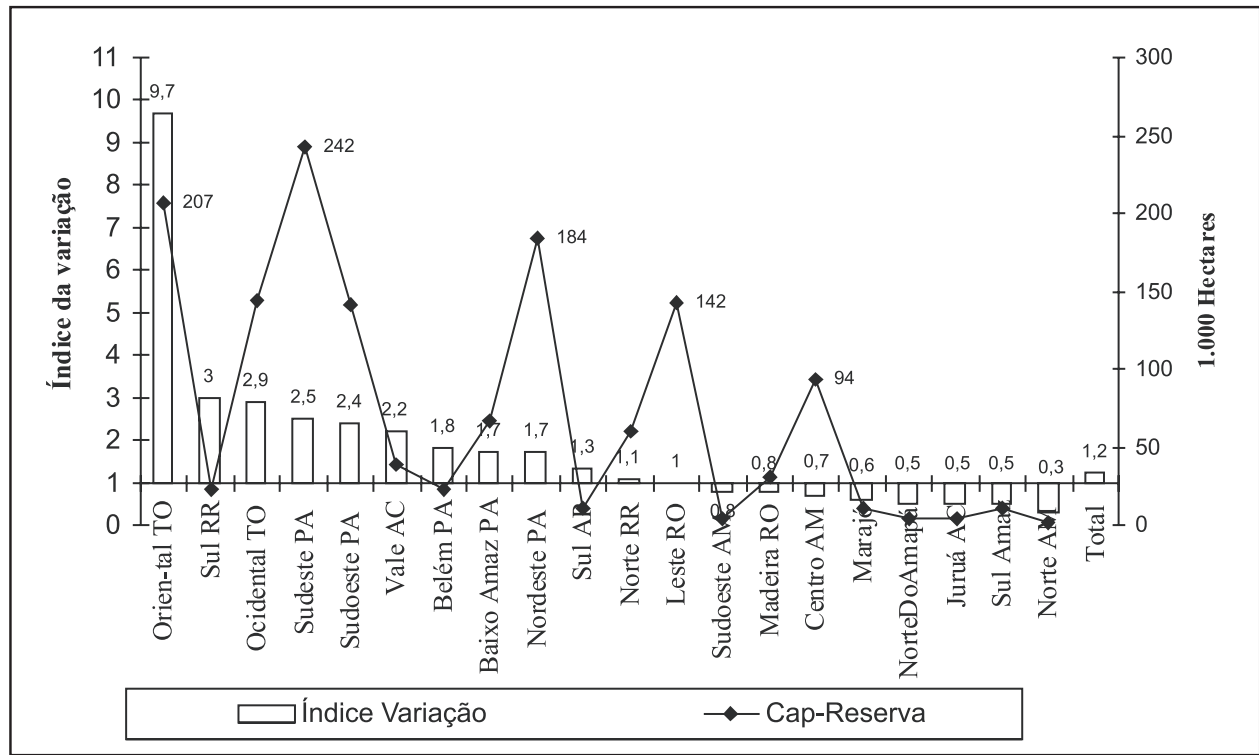

Gráfico 2: Diferencial ${ }^{4}$ entre a produtividade monetária ${ }^{1}$ das culturas permanentes ${ }^{2}$ e a das culturas temporárias ${ }^{3}$, por mesorregiões (1995).

Fonte: IBGE. Censo Agropecuário: Estado do Pará, 1995-96. Todos os Estados da Região Norte.

Notas:

1 Valor Bruto da Produção por unidade de área utilizada, incluindo pousio.

2 Todas as culturas permanentes constantes do Censo, exceto 0 açaí.

${ }^{3}$ Todas as culturas temporárias (não apenas as da shifting cultivation) constantes do Censo.

${ }^{4}$ Produtividade das culturas permanentes sobre produtividade das temporárias.

Em segundo lugar, porque a elevação da produtividade, expandindo a oferta, tem exposto a elevada sensibilidade do preço do conjunto de produtos (ver, no Gráfico 3, o índice efeito-preços). Tal elasticidade, que se reflete na forte redução da produtividade monetária,

${ }^{5}$ Sobre o aparato de $C \& T$ e seus progressos e possibilidades, bem como sobre o papel do crédito nas culturas permanentes da fruticultura, ver Costa, Andrade e Fiock (2004). 
por uma parte associa-se a aspectos infra-estruturais - capital social básico, externalidades físicas; por outra, deriva de configurações contratuais e organizacionais, nas quais se verifica uma forte assimetria entre os agentes urbanos (comércio e indústria) e rurais (produtores), mesmo quando o processamento industrial das frutas cresce a rápidas taxas anuais de $6 \%$ ao ano (demonstramos suficientemente esse ponto em Costa et al., 1994 e Costa e Inhetvin, 2005).

No conjunto da Região Norte, a área das culturas permanentes tem se expandido continuamente desde 1997. Após ter se situado em torno de 700 mil hectares entre 1990 e 1996, atingiu, em 2003, 850 mil hectares ${ }^{6}$. A relação com a área das culturas temporárias da shifting cultivation deteriorou-se sistematicamente também até 1997, recuperando-se a partir daí.

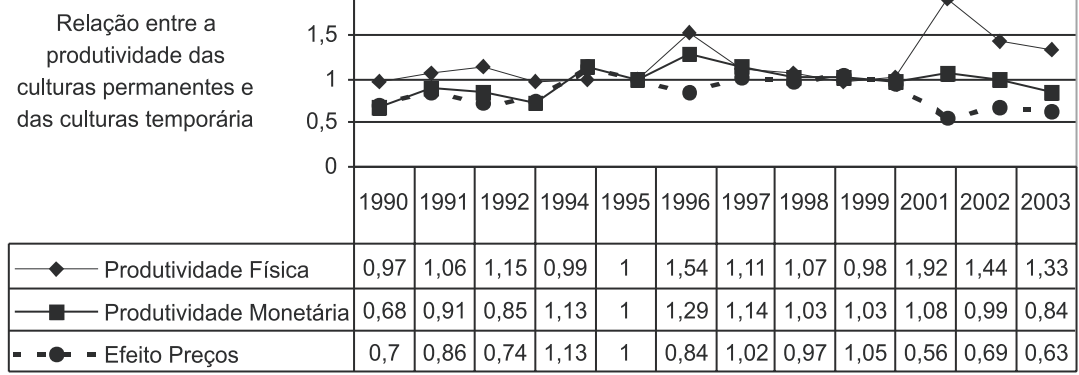

Gráfico 3: Evolução dos índices que expressam o diferencial 5 entre a produtividade monetária ${ }^{1}$ das culturas permanentes ${ }^{3}$ e a das culturas temporárias ${ }^{4}$ da shifting cultivation, dos índices que expressam 0 diferencial ${ }^{5}$ da produtividade física ${ }^{2}$ dos mesmos grupos de produtos e dos índices que expressam as diferenças entre os primeiros e os últimos (efeito-preços) ${ }^{6}$ (1990 a 2003).

Fonte: IBGE, PAM. Todos os Estados da Região Norte.

\section{Notas}

${ }^{1}$ Valor Bruto da Produção por unidade de área utilizada, sem incluir o pousio. Esse resultado sobreestima a produtividade das culturas temporárias. Consideramos isso irrelevante para a análise, porque nos importa mais o movimento.

\footnotetext{
${ }^{6}$ Registre-se, para frisar a importância do componente institucional, que a área total financiada pelo FNO entre 2000 e 2005, segundo informações do BASA, foi de 94.063 ha em toda a Região Norte.
} 
2 Produto Real dividido por área total. Produto Real é a soma, para cada ano, do produto das quantidades produzidas de cada cultura pelo preço médio respectivo do período. Os números índices desses valores anuais expressam a flutuação conjunta das quantidades de todos os produtos. Os números índices desses valores divididos pela área total expressam a flutuação da produtividade física conjunta de todos os produtos.

${ }^{3}$ Todas as culturas permanentes constantes da PAM, exceto 0 açaí.

${ }^{4}$ As culturas temporárias da shifting cultivation: arroz, milho, mandioca, feijão, fava, etc.

5 Índice $(1995=1)$, respectivamente, da produtividade monetária e da produtividade física das culturas permanentes sobre índices correspondentes para as culturas temporárias.

${ }^{6}$ Divisão dos índices que expressam os diferenciais da produtividade monetária pelos da produtividade física.

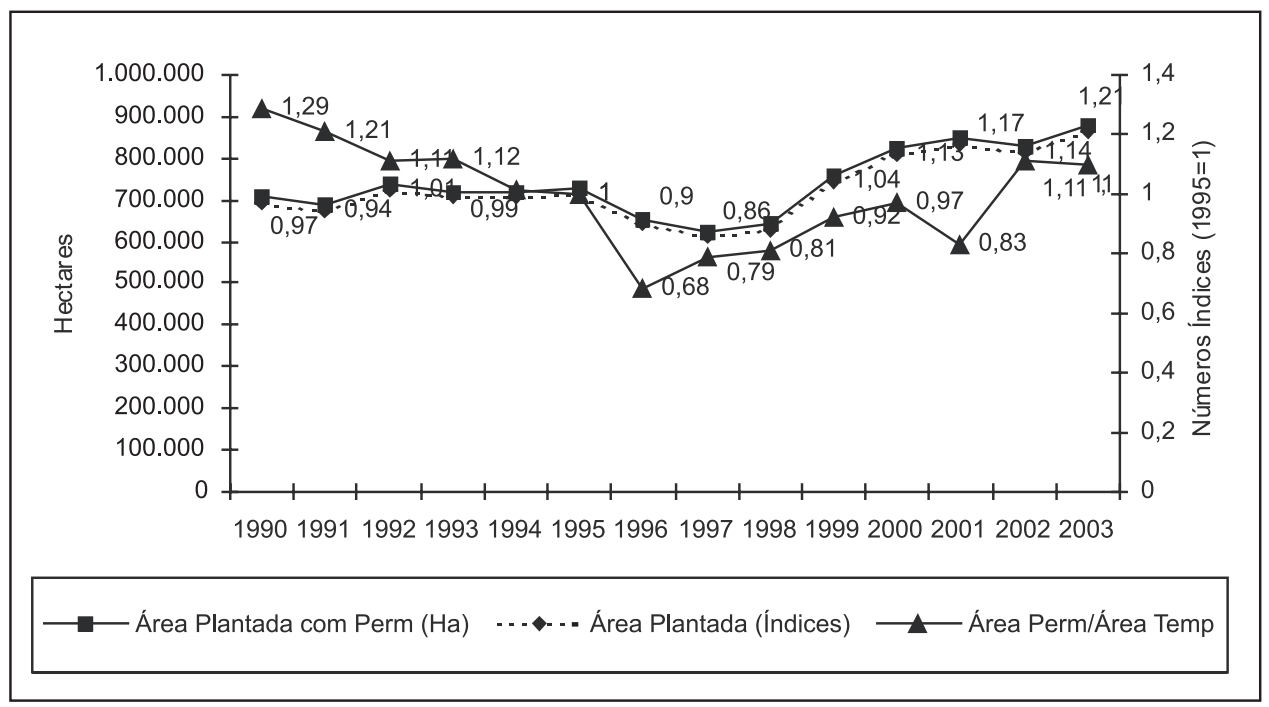

Gráfico 4: Evolução da área com culturas permanentes e da relação entre área com culturas permanentes e área com culturas temporárias (1990 a 2003).

Fonte: IBGE, PAM e IBGE. Censo Agropecuário 1995-96. Todos os estados da Região Norte.

O processo produziu, entre 1995 e 2003, perto de 300 mil hectares de capoeiras-reserva (considerando-se o índice de conversão encontrado para toda a região, de 1,98 hectare de capoeira-reserva para cada 1 hectare de cultura permanente, multiplicado por 150 mil hectares adicionais de culturas permanentes). No mesmo período, formaram-se adicionalmente 165 mil hectares de culturas temporárias, dos quais 
aproximadamente $38 \%$ (considerada a estimativa de 771 mil hectares de capoeira-capital num montante de 2 milhões de hectares dedicados a culturas temporárias) são capoeiras-capital.

Isso posto, o saldo a computar seria, na dinâmica da formação de capoeiras-reserva em relação à capoeira-capital, de aproximadamente 237 mil hectares em favor das primeiras.

\subsection{CAPOEIRA-SUCATA PROVINDA DA PECUÁRIA EXTENSIVA VERSUS CAPOEIRA-RESERVA PROVINDA DA PECUÁRIA INTENSIVA}

Segundo os dados do Censo, em 1995, 48\% do rebanho total provinham de estabelecimentos com rebanhos de até 200 cabeças, com médias, todavia, em torno de 19 cabeças. Nesse grupo de estabelecimentos, a pecuária faz parte de sistemas de produção complexos e diversificados, dominantemente camponeses, pouco especializados, nos quais o valor da produção da pecuária representa apenas $24 \%$ do total. Ademais, do valor da produção pecuária bovina, $76 \%$ provêm da produção de leite e de seus derivados. Essas características dotam esses estabelecimentos de uma capacidade de suporte de 0,9 cab/ha - a maior de todas as classes de rebanho (cf. Gráfico 2). Não teremos aqui nosso foco para a observação da pecuária extensiva.

A pecuária de corte, por seu turno, representa $80 \%, 89 \%, 94 \%$ e $97 \%$ do valor da produção pecuária dos estabelecimentos com classes de rebanhos de 201 a 1000 cabeças, 1001 a 3000 cabeças, 3001 a 8000 cabeças e mais de 8000 cabeças, respectivamente. Desses, os estabelecimentos do primeiro intervalo, com média de 392 cabeças, representam a maior proporção do rebanho $(30 \%$ do total e $58 \%$ da pecuária de corte). Os estabelecimentos com rebanhos entre 1001 e 3000 , com média de 1.455 cabeças, representam $13 \%$ do rebanho total, $25 \%$ do rebanho de corte. Os estabelecimentos com rebanhos entre 3001 e 8000 , com média de 4318 cabeças, representam $8 \%$ do rebanho total e $15 \%$ do rebanho para corte. Por fim, os estabelecimentos com mais de 8000 cabeças, com média de 12.849 cabeças, representam 1\% do rebanho total e $2 \%$ do rebanho para corte. A capacidade de suporte ou intensidade tecnológica dos estabelecimentos com rebanhos entre 201 e 1000 cabeças foi de 0,6 cab/ha: praticamente a mesma das duas classes seguintes, respectivamente 0,59 e 0,56 cab/ha. Só nos estabelecimentos com rebanhos acima de 8000 cabeças é que esse parâmetro aumenta significativamente, para 0,78 cab/ha (ver Gráfico 
5). A rentabilidade, por sua vez, medida pela renda líquida por trabalhador equivalente aplicado na produção, dá um salto de R\$1.509 para R \$ 2.503 do intervalo de 201 a 1000 cabeças para o seguinte, entre 1001 e 3000 cabeças, crescendo a partir daí continuamente, atingindo $R \$ 2.929$ para o intervalo entre 3001 e 8000 cabeças e $R \$$ 2.995, para os rebanhos acima de 8000 cabeças. Em resumo: para o total da Região Norte, em 1995, na pecuária de corte, a rentabilidade correlaciona-se positivamente com a escala e parece ser indiferente à intensidade do uso da terra.

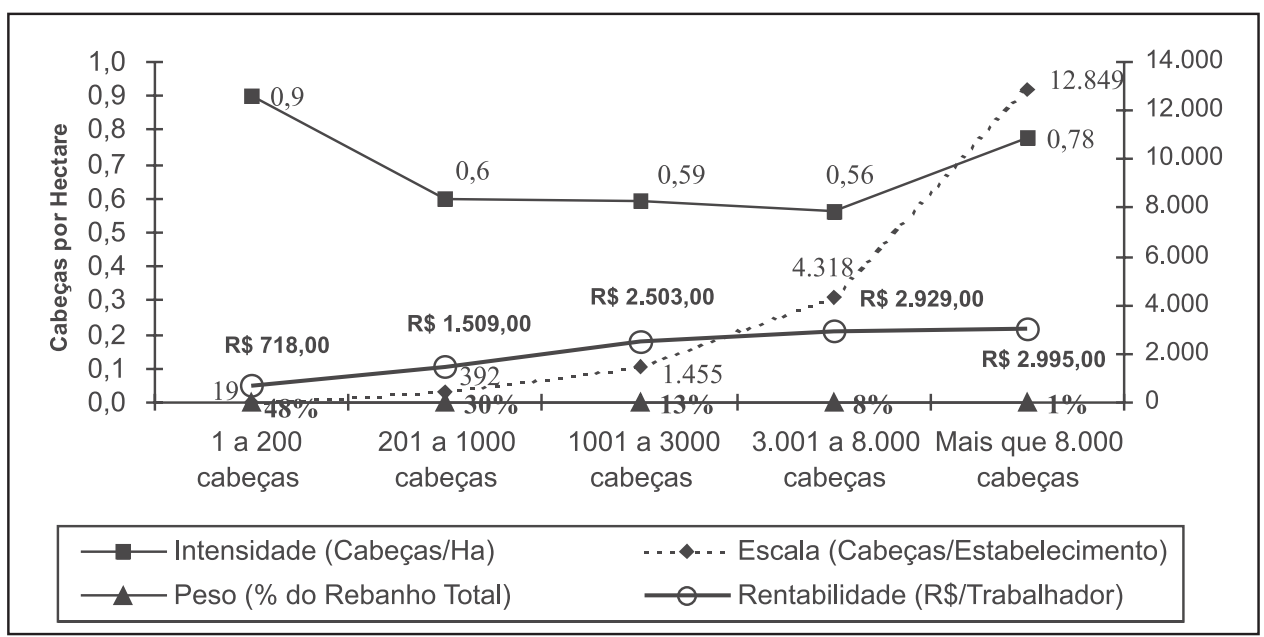

Gráfico 5: Proporção (\%) do rebanho associada à escala média (cabeças por estabelecimento) e à intensidade (cabeça por hectare) da pecuária bovina na Região Norte (1995).

Fonte: IBGE. Censo Agropecuário: Estado do Pará, 1995-96. Tabulações especiais do autor.

Em 2002 e em 2003, a FNP fez pesquisas de custos anuais e rentabilidade da pecuária de corte em fazendas de sete regiões da Amazônia Legal - quatro em Mato Grosso, duas no Pará, uma em Rondônia e duas no Tocantins - , distinguindo três níveis de intensificação tecnológica (extensiva 0,6 cab/ha, semi-intensiva 0,8 cab/ha e intensiva $1 \mathrm{cab} / \mathrm{ha}$ ) e duas escalas de produção diferentes (de 500 e de 5000 cabeças). Foram considerados dois indicadores de rentabilidade: o pay back, como rentabilidade sobre o patrimônio total, e a rentabilidade por unidade de área. 
Calculadas as médias para a Amazônia, encontramos os resultados apresentados no Gráfico 6 para 2003. Podem-se tirar as seguintes conclusões:

a) a rentabilidade do nível mais extensivo $(0,64 \mathrm{cab} / \mathrm{ha})$ é a maior rentabilidade das unidades produtivas com média de 500 cabeças;

b) à proporção que o nível tecnológico aumenta (passa para 0,86/cab/ ha), as unidades produtivas de menor escala (500 cabeças) têm menor eficiência pelos dois indicadores, chegando a ter rendimento negativo no nível tecnológico mais elevado (1,02/cab/ha);

c) em maior escala (5000 cabeças), o nível tecnológico mais baixo (0,61 $\mathrm{cab} / \mathrm{ha}$ ) tem rentabilidade em torno de quatro vezes superior à de menor escala no mesmo nível tecnológico;

d) à proporção que o nível tecnológico se eleva (escala de 5000 cabeças), a rentabilidade por unidade de área cresce - apesar do pay back reduzir em nível intermediário $(0,79 \mathrm{cab} / \mathrm{ha})$ - , atingindo um máximo no nível mais alto de intensidade $(0,98 \mathrm{cab} / \mathrm{ha})$. 


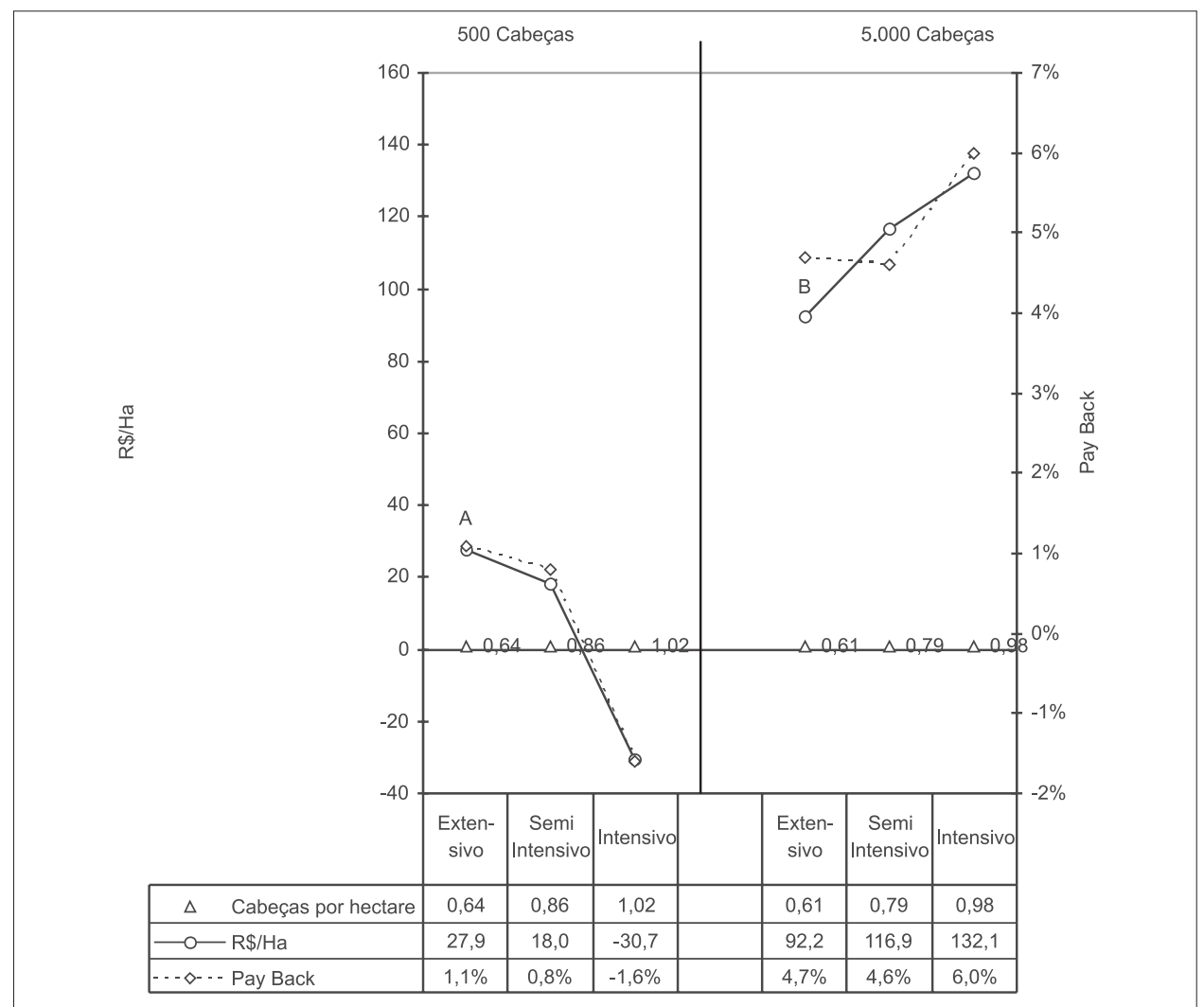

Gráfico 6: Pay backs (\%) e rendimento por hectare (R\$/ha) para diferentes escalas de produção e diferentes níveis tecnológicos para a Amazônia e para o resto do Brasil (2003).

Fonte: FNP (2003).

Tais resultados são completamente compatíveis com os números do Censo. Em conjunto com eles, indicam que a intensificação na pecuária de corte, partindo da escala média dos estabelecimentos que têm a metade do rebanho com esse fim, não é path-efficient - não produz uma trajetória consistente -, conforme se definiu acima (ver 2.1, relação 6 ): se os estabelecimentos com rebanho médio de 400 cabeças mudassem a tecnologia para uma intensidade de 0,86 cab/ha, eles teriam a rentabilidade diminuída em 35\%, aproximadamente; se forçassem a adoção de tecnologias que elevassem a intensidade para 1,02 cabeças, a rentabilidade cairia a taxas mais elevadas ainda.

Poder-se-ia, todavia, ter um contexto de rentabilidade crescente mantido a baixa intensidade de 0,6 cab/ha, isto é, prevalecendo à solução 
tecnológica inferior. Com efeito, mantida a solução tecnológica mais extensiva, aquela que gera mais capoeira-sucata, a rentabilidade poderia crescer sistematicamente. Para demonstrar isso, façamos dois cálculos, o primeiro com os dados do Censo e o segundo com os dados da FNP:

a) partindo dos dados do Censo (Gráfico 4), o coeficiente angular da reta que une o ponto que representa a escala média de 392 cabeças para rendimento por unidade de trabalhador de $\mathrm{R} \$ 1.509,00$ ao ponto que representa a escala de 1455 cabeças para rendimento de $\mathrm{R} \$ 2.503,00$ é de 0,94 , o que leva a um incremento na rentabilidade de $6 \%$ para cada 100 cabeças a mais na escala de produção; se a reta se estende até o ponto da escala de 4318 cabeças com a rentabilidade de $R \$ 2.929,00$, considerando assim todos os pontos de intensidade em torno de $0,6 \mathrm{cab} / \mathrm{ha}$, o coeficiente angular cai para 0,36, o que leva a um acréscimo médio 2,3\% para cada 100 cabeças a mais na escala média;

b) partindo dos dados da FNP (Gráfico 5), o coeficiente angular de um reta que vai do ponto $A$ (rentabilidade por unidade de área de $\mathrm{R} \$$ 27,9 e escala de 500 cabeças para a menor intensidade de 0,6 cab/ ha) ao ponto $B$ (rentabilidade $R \$ 92,6$ para escala de 5000 cabeças para a mesma intensidade de 0,6 cab/ha) no Gráfico 4 seria 0,014, de modo que, a cada 100 cabeças a mais no rebanho médio, acrescese $R \$ 1,40$, isto é, $5 \%$, na rentabilidade.

Há dois vetores institucionais que podem estar corroborando os rendimentos crescentes dos procedimentos tecnológicos que mais geram capoeiras-sucata. De um lado, a institucionalidade (ou a falta dela) que permite a geração de capoeira-sucata como uma realidade estrutural da dinâmica agrária da Região. Discutir os fundamentos legais, organizacionais e políticos que estão na base dessa questão foge ao escopo deste artigo. Todavia, importa mencionar que não se trata de um fato economicamente irrelevante. Podemos perceber seu significado no payoff dos agentes se considerarmos a diferença na rentabilidade por unidade de área nos cálculos que incluem ou não as capoeiras-sucata. Se dividirmos toda a renda líquida da pecuária, $R \$ 1,5$ bilhão, pela área de pasto, 24,3 milhões de hectares, obteremos uma rentabilidade por hectare de $\mathrm{R} \$ 61$; ao incluirmos as capoeiras-sucata geradas por 2,3 milhões de hectares no cálculo, a rentabilidade cairia para $\mathrm{R} \$ 56$ por 
hectare. Poder-se-ia afirmar, portanto, que a existência de capoeirassucata, ou das condições institucionais que a corroboram, explicaria o payoff dos agentes de modo diretamente proporcional a essa diferença.

De outro lado, desenvolvimentos tecnológicos que atuam mais sobre os rebanhos do que sobre as condições das pastagens e 0 crédito institucionalizado que internaliza esses avanços particularmente os créditos provenientes do FNO - contribuem fortemente para o incremento da escala de produção. A propósito, destaque-se que, do total de crédito do FNO destinado à agropecuária no período de 2000 a 2005 - aproximadamente R\$ 3 bilhões, em torno de 55\% estão direta ou indiretamente ligados à pecuária de corte, associada com culturas temporárias. Isso corresponde, a preços correntes, a R\$270 milhões por ano de investimentos com crédito subsidiado no setor.

O crescimento do rebanho na Região Norte tem sido notável desde o Censo: de 17,3 milhões de cabeças em 1995, passou para 24,5 milhões em 2000, chegando a 34 milhões em 2003 (IBGE, 2005). A discussão anterior permite-nos estimar que o pasto necessário teria passado de 24,4 para 47,9 milhões de hectares. Permite-nos, também, assumir que os pressupostos da formação de capoeira-sucata mantêm-se fortes na região, pelo menos iguais aos do ano do Censo, quando as capoeirassucata representavam $9,4 \%$ do total de pasto. Assim, entre o Censo e o ano de 2003, teria havido a formação de adicionais 2,2 milhões de hectares de capoeiras-sucata, o que eleva para 4,5 milhões de hectares o montante dessa forma de capoeira em toda a região.

\section{5 - A FORMAÇÃO DE CAPOEIRA-SUCATA E A SHIFTING CULTIVATION: A INTERVENÇÃO INSTITUCIONAL DA C\&T}

Em 5.1 deduzimos que há um vetor de formação de capoeirassucata associado à shifting cultivation. Não conseguimos, entretanto, encontrar uma variável no Censo que permitisse o seu dimensionamento. Tampouco há evidências estatisticamente relevantes de sua ocorrência. Não obstante, é razoável a hipótese de que a shifting cultivation apresenta crises de produtividade que podem gerar capoeiras-sucata e que tais crises têm a ver com a redução do tempo de formação da capoeira - com sua utilização precoce - e com o aproveitamento ineficiente dos seus elementos permitidos pelo uso do fogo.

Quais as possibilidades de uma mudança tecnológica na agricultura de derruba e queima, que poderia torná-la mais eficiente e menos 
formadora de capoeira-sucata? Não há, como já se mencionou, na prática da produção efetiva dos camponeses, muitas experiências a respeito. Há, contudo, no campo da pesquisa agronômica, encaminhamentos significativos, os quais importa avaliar. 0 mais importante deles é o representado pelo projeto SHIFT-Capoeira, resultado de um convênio entre a Empresa Brasileira de Pesquisa Agropecuária-Centro de Pesquisa Agropecuária do Trópico Úmido (EMBRAPA-CPATU) e o Zentral Institut für Entwicklungsforschung, da Universidade de Bonn.

O SHIFT-Capoeira tem duas linhas de investigação em pesquisa e desenvolvimento $(P \& D)$ : a que busca alternativas para a redução da biomassa das capoeiras e a que procura reduzir as perdas por lixiviação e volatização dos nutrientes. A primeira resultou em uma série de estudos para propor soluções de base biológica e botânica, cujo objetivo central seria encontrar espécies de crescimento rápido para o enriquecimento das capoeiras (KATO et al., 2004a, 2004b). A segunda levou a uma série de estudos sobre soluções mecânicas alternativas, fixando-se na obtenção de equipamentos de trituração da capoeira (DENICH et al., 2004).

De acordo com a hipótese central de trabalho nessas pesquisas, os nutrientes contidos na biomassa da capoeira levariam um tempo maior para serem incorporados ao solo a partir da condição de mulch resultante da trituração do que a partir da condição de cinzas resultantes da queima. Ademais, cogita-se, poder-se-ia contar, adotado o primeiro método, com os benefícios paralelos tanto da infinitamente menor emissão de $\mathrm{CO}^{2}$ e perda aérea de nutrientes, quanto da capacidade de melhoria das condições biológicas, físicas e mecânicas do solo (cf. COSTA; VON BRAUN, 2000; FREITAS, 2005; VIELHAUER; KANASHIRO; SÁ, 1997).

Desses dois focos, duas condições da capoeira, submetida ao manejo propiciado pelas técnicas de mulch, foram consideradas nas pesquisas de $P \& D$ : numa, ela presta serviços de seqüestro de carbono e outros serviços ambientais; na outra, ela é estritamente a base para a produção de insumos agrícolas. Na primeira condição, pressupõe-se a capoeira como produção (gerando produtos capazes de se tornarem mercadorias reconhecidamente seus) autônoma em relação à agricultura; na segunda condição, toda a contribuição da capoeira aos sistemas de produção materializa-se na produção e na produtividade agrícola.

A última condição é a que se considerará na análise que segue. Com base nela, fizemos análises de custo e de rentabilidade das técnicas de trituração desenvolvidas na pesquisa. 


\subsection{A PESQUISA DE CUSTOS: FUNDAMENTOS}

Nossos esforços orientaram-se para a verificação dos efeitos das inovações propostas pelo SHIFT-Capoeira na rentabilidade líquida do trabalho: proxy do payoff dos camponeses, clientela presumida das tecnologias resultantes. As avaliações concentraram-se nos métodos mecânicos, visto que os biológicos requeriam um tempo maior. Importava-nos, sobretudo, verificar em que medida a mecanização da shifting cultivation constituiria uma alternativa viável para a tendência de intensificação pela complexificação dos sistemas produtivos a partir da introdução de culturas permanentes que tendencialmente (historicamente) vinham se afirmando na Região.

Com base em uma amostra de 24 famílias camponesas da Travessa do Cumaru, em Igarapé-Açu, fez-se um survey relativo ao ano agrícola de 1999 (que seria o to da análise). Em seguida, separaram-se dois grupos de 12 famílias: um grupo adotou a técnica de mulch (trituração da capoeira) e o outro não - manteve a técnica tradicional de derruba e queima. $A$ indicação da extensão da capoeira a ser triturada $\left(A_{a}{ }^{*}\right)$ ou derrubada e queimada $\left(A_{a}\right)$ e do que deveria ser plantado ficou a critério dos titulares dos estabelecimentos, sendo garantida, todavia, para a melhor decisão, a orientação técnica necessária. Uma equipe formada por um agrônomo, um técnico agrícola e uma auxiliar de pesquisa agrícola acompanhou durante três anos o desempenho de cada estabelecimento, anotando mês a mês os resultados relativos aos custos e às receitas da produção agrícola, plantio a plantio (cada um identificado individualmente). Gerou-se um banco de dados com uma tabela com os dados de cadastro dos estabelecimentos, outra com os dados de plantio das culturas, outra com os dados de aplicação de trabalho familiar por plantio e outra com os dados de custos por plantio, aí incluídos os dados relativos à mecanização, à aplicação de insumos químicos e ao trabalho de terceiros. A tabulação desses dados permitiu os cálculos que seguem.

A seguir far-se-ão três tipos de análise. A primeira observará a composição da renda líquida total, considerando todas as possibilidades das famílias: as que derivam diretamente da produção rural associada ao acervo de trabalho e terra da família e as que derivam de aplicações outras desse acervo (aplicação de trabalho em atividades rurais de outros estabelecimentos ou em atividades não rurais e no arrendamento eventual da terra). Na avaliação comparativa de desempenho, observarse-á a rentabilidade por unidade de trabalhador equivalente. A segunda análise focará a renda líquida derivada estritamente do conjunto dos plantios associados à utilização da biomassa resultante da capoeira. Nesse caso, verificar-se-á a rentabilidade do trabalho e da terra mobilizados. 
A terceira análise deter-se-á no desempenho das culturas trabalhadas com recursos obtidos da capoeira, seja pela técnica de trituração, seja pela técnica de derruba e queima.

\subsection{Comparação da rentabilidade dos estabelecimentos}

Nos três anos estudados, a renda líquida total real, isto é, descontada a inflação, por trabalhador-equivalente das famílias pesquisadas, caiu de R\$4.588 para R\$3.470 (cf. Gráfico 7). Entre as famílias que não trituraram, a queda foi mais significativa, indo de $R \$$ $5.763,00$ em 2000 para $R \$ 3.384,00$ em 2002 , passando por $R \$ 3.805,00$ no ano anterior. Entre as famílias que utilizaram técnicas de mulch, houve um crescimento da rentabilidade do trabalho de 2000 para 2001, passando de $R \$ 3.579,00$ para $R \$ 3.805,00$, voltando no ano seguinte ao nível inicial de $\mathrm{R} \$ 3.571,00$.

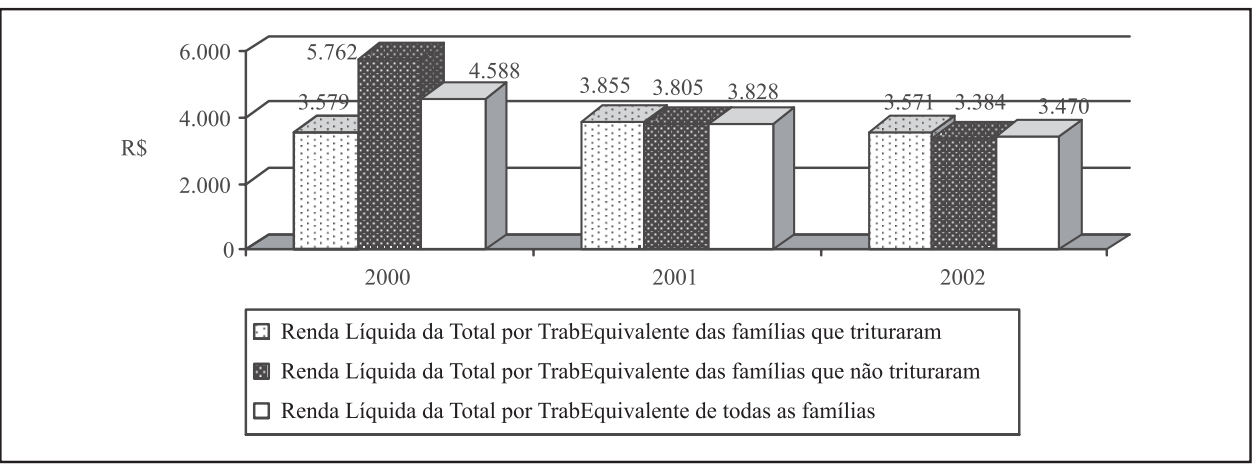

Gráfico 7: Evolução da renda líquida derivada de todas as atividades por trabalhador equivalente (a preços constantes em R\$ de 2002).

Fonte: Tabelas 3, 4 e 5. Atualização dos preços para 2002 feita pelo IGP/FGV.

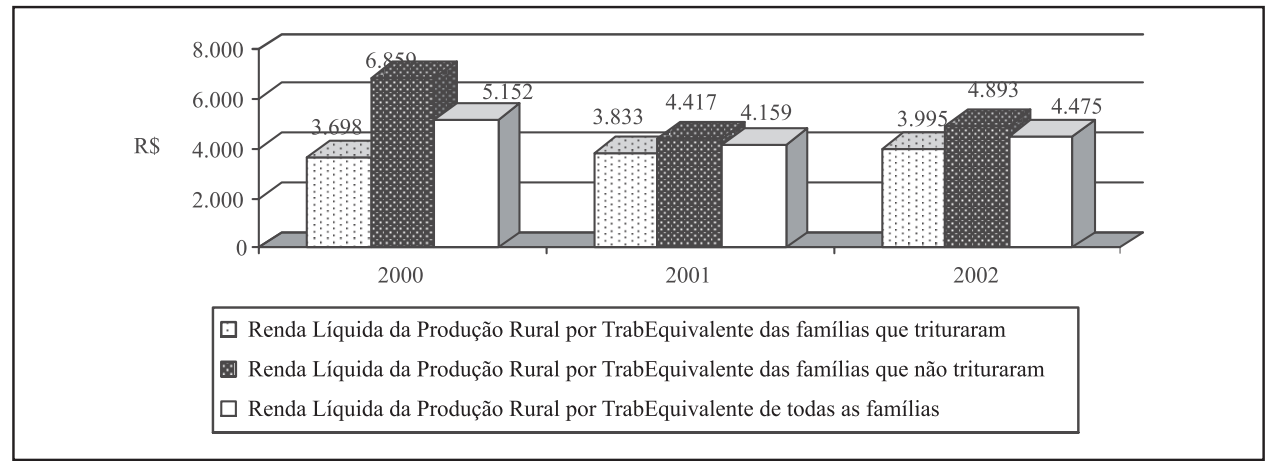

Gráfico 8: Evolução da renda líquida derivada da produção rural por trabalhador equivalente (a preços constantes em $\mathrm{R} \$$ de 2002).

Fonte: Tabelas 3, 4 e 5. Atualização dos preços para 2002 feita pelo IGP/FGV. 
Tabela 3: Rentabilidade total e por trabalhador equivalente dos estabelecimentos que adotaram a trituração da capoeira ( $R$ \$ preços correntes).

\begin{tabular}{|c|c|c|c|}
\hline Descrição & 2000 & 2001 & 2002 \\
\hline I. Renda bruta total da produção rural ${ }^{1}$ & $46.804,40$ & $59.271,22$ & $72.140,38$ \\
\hline (-) Custo com fertilizantes e inseticidas ${ }^{2}$ & $2.273,50$ & $6.868,40$ & $7.535,25$ \\
\hline (-) Custo com trabalho de terceiros & $1.836,00$ & $4.408,28$ & $9.021,85$ \\
\hline (-) Custo com mecanização & 301,50 & $4.443,70$ & $1.358,70$ \\
\hline II. Renda líquida total da produção rural & $42.393,40$ & $43.550,84$ & $54.224,58$ \\
\hline$(+)$ Renda de trabalhos para terceiros ${ }^{5}$ & $4.575,00$ & $12.712,50$ & $17.243,00$ \\
\hline$(+)$ Renda por seguridade e transferências ${ }^{6}$ & $6.040,00$ & $12.804,00$ & $18.725,00$ \\
\hline \multirow[t]{2}{*}{ III. Renda líquida total das famílias ${ }^{7}$} & $53.008,40$ & $69.067,34$ & $90.192,58$ \\
\hline & $4.799,71$ & $4.308,69$ & $4.072,00$ \\
\hline III.2. Trabalho aplicado no total de atividades $(\mathrm{D} / \mathrm{H})^{8}$ & $6.200,77$ & $6.794,54$ & $7.576,60$ \\
\hline III.4. Renda líquida anual por trabalhador equivalente & & & \\
\hline na agriculturra ${ }^{9}$ & $2.649,75$ & $3.032,30$ & $3.994,93$ \\
\hline $\begin{array}{l}\text { III.5. Renda líquida anual por trabalhador e } \\
\text { no total }{ }^{10}\end{array}$ & $2.564,60$ & $3.049,54$ & $3.571,23$ \\
\hline
\end{tabular}

Fonte: Pesquisa de campo, Projeto ENV-44, NAEA.

Notas:

${ }^{1}$ Soma de toda a produção rural ao preço de cada transação. Para a produção não vendida (autoconsumo), utilizou-se o preço médio do produto para todo o grupo. As culturas monitoradas para comparação foram: maracujá, arroz, feijão, macaxeira, mandioca, milho e pimenta-doce. Além dessas, considerou-se o valor da produção das seguintes culturas: abacate, abiu, abricó, acácia, açaí, acerola, ameixa, bacaba, banana, cacau, café, caju, coco-da-baía, cupuaçu, goiaba, graviola, ingá, jaca, jambo, laranja, lima, limão, mamão, manga, muruci, pimenta-do-reino, pupunha, tangerina, taperebá, urucum, abóbora, algodão herbáceo, cana-de-açúcar, melancia, pepino e outras hortaliças.

${ }^{2}$ Incluiu todas as formas de fertilizantes e inseticidas adquiridos no mercado.

${ }^{3}$ Todas as formas de trabalho remunerado de terceiros.

${ }^{4}$ Custo de aplicação dos equipamentos para a trituração da capoeira a R\$ 500 .

${ }^{5}$ Renda de trabalho aplicado em atividades rurais em estabelecimentos de terceiros e outras rendas derivadas da aplicação do trabalho familiar.

${ }^{6}$ Renda derivada de transferências de governo.

${ }^{7}$ Total de trabalho familiar e de terceiros aplicado na produção rural.

${ }^{8} 0$ item anterior acrescido do trabalho fora do estabelecimento.

${ }^{9} \mathrm{O}$ item III dividido por III.1 multiplicado por 300.

${ }^{10} \mathrm{O}$ item III dividido por III.2 multiplicado por 300 . 
Tabela 4: Rentabilidade total e por trabalhador equivalente dos estabelecimentos que não adotaram a trituração da capoeira ( $\mathrm{R} \$$ preços correntes).

\begin{tabular}{|c|c|c|c|}
\hline Descrição & 2000 & 2001 & 2002 \\
\hline I. Renda bruta total da produção rural ${ }^{1}$ & $77.467,11$ & $79.608,85$ & $92.848,25$ \\
\hline (-) Custo com fertilizantes e inseticidas ${ }^{2}$ & $8.683,75$ & $10.203,20$ & $8.069,35$ \\
\hline (-) Custo com trabalho de terceiros ${ }^{3}$ & $1.817,71$ & $6.084,34$ & $8.470,63$ \\
\hline (-) Custo com mecanização ${ }^{4}$ & - & - & \\
\hline II. Renda líquida total da produção rural & $66.965,65$ & $63.321,31$ & $76.308,27$ \\
\hline$(+)$ Renda de trabalhos para terceiros ${ }^{5}$ & $5.358,00$ & $12.650,00$ & $19.135,00$ \\
\hline$(+)$ Renda por seguridade e transferências ${ }^{6}$ & $1.057,00$ & $2.448,00$ & $6.470,00$ \\
\hline III. Renda líquida total das famílias & $73.380,65$ & $78.419,31$ & $101.913,2$ \\
\hline III.1. Trabalho aplicado na agricultura (D/H) ${ }^{7}$ & $4.087,26$ & $5.436,55$ & $4.678,70$ \\
\hline III.2. Trabalho aplicado no total de atividades $(\mathrm{D} / \mathrm{H})^{8}$ & $5.332,26$ & $7.815,55$ & $9.033,70$ \\
\hline $\begin{array}{l}\text { III.4. Renda líquida anual por trabalhador equivalente } \\
\text { na agricultura }{ }^{9}\end{array}$ & $4.915,20$ & $3.494,20$ & $4.892,91$ \\
\hline $\begin{array}{l}\text { III.5. Renda líquida anual por trabalhador equivaler } \\
\text { no total }{ }^{10}\end{array}$ & $4.128,49$ & $3.010,13$ & $3.384,44$ \\
\hline
\end{tabular}

Fonte: Pesquisa de campo, Projeto ENV-44, NAEA.

Notas:

${ }^{1}$ Soma de toda a produção rural ao preço de cada transação. Para a produção não vendida (autoconsumo), utilizou-se o preço médio do produto para todo o grupo.

${ }^{2}$ Incluiu todas as formas de fertilizantes e inseticidas adquiridos no mercado.

${ }^{3}$ Todas as formas de trabalho remunerado de terceiros.

${ }^{4}$ Custo de aplicação dos equipamentos para a trituração da capoeira a $\mathrm{R} \$$ 500.

${ }^{5}$ Renda de trabalho aplicado em atividades rurais em estabelecimentos de terceiros e outras rendas derivadas da aplicação do trabalho familiar.

${ }^{6}$ Renda derivada de transferências de governo.

${ }^{7}$ Total de trabalho familiar e de terceiros aplicado na produção rural.

${ }^{8} \mathrm{O}$ item anterior acrescido do trabalho fora do estabelecimento.

${ }^{9} \mathrm{O}$ item III dividido por III.1 multiplicado por 300.

${ }^{10} \mathrm{O}$ item III dividido por III.2 multiplicado por 300 . 
Tabela 5: Rentabilidade total por trabalhador equivalente de todos os estabelecimentos que participaram da pesquisa ( $\mathrm{R}$ preços correntes).

\begin{tabular}{|c|c|c|c|}
\hline Descrição & 2000 & 2001 & 2002 \\
\hline I. Renda bruta total da produção rural $^{1}$ & $124.271,51$ & $138.880,0$ & $164.988,6$ \\
\hline (-) Custo com fertilizantes e inseticidas ${ }^{2}$ & $10.957,25$ & $17.071,60$ & $15.604,60$ \\
\hline (-) Custo com trabalho de terceiros ${ }^{3}$ & $3.653,71$ & $10.492,62$ & $17.492,49$ \\
\hline (-) Custo com mecanização ${ }^{4}$ & 301,50 & $4.443,70$ & $1.358,70$ \\
\hline II. Renda líquida total da produção rural & $109.359,05$ & $106.872,1$ & $130.532,8$ \\
\hline$(+)$ Renda de trabalhos para terceiros ${ }^{5}$ & $9.933,00$ & $25.362,50$ & $36.378,00$ \\
\hline$(+)$ Renda por seguridade e transferências ${ }^{6}$ & $7.097,00$ & $15.252,00$ & $25.195,00$ \\
\hline III. Renda líquida total das famílias & $126.389,05$ & $147.486,6$ & $192.105,8$ \\
\hline III.1. Trabalho aplicado na agricultura $(\mathrm{D} / \mathrm{H})^{7}$ & $8.886,97$ & $9.745,24$ & $8.750,70$ \\
\hline III.2. Trabalho aplicado no total de atividades $(\mathrm{D} / \mathrm{H})^{8}$ & $11.533,03$ & $14.610,09$ & $16.610,30$ \\
\hline $\begin{array}{l}\text { III.4. Renda líquida anual por trabalhador equivalente } \\
\text { na agricultura } 9\end{array}$ & $3.691,67$ & $3.289,98$ & $4.475,05$ \\
\hline $\begin{array}{l}\text { III.5. Renda líquida anual por trabalhador equivalen } \\
\text { no total }\end{array}$ & $3.287,66$ & $3.028,45$ & $3.469,64$ \\
\hline
\end{tabular}

Fonte: Pesquisa de campo, Projeto ENV-44, NAEA.

Notas:

${ }^{1}$ Soma de toda a produção rural ao preço de cada transação. Para a produção não vendida (autoconsumo), utilizou-se o preço médio do produto para todo o grupo.

${ }^{2}$ Incluiu todas as formas de fertilizantes e inseticidas adquiridos no mercado.

${ }^{3}$ Todas as formas de trabalho remunerado de terceiros.

${ }^{4}$ Custo de aplicação dos equipamentos para a trituração da capoeira a $\mathrm{R} \$ 500$.

${ }^{5}$ Renda de trabalho aplicado em atividades rurais em estabelecimentos de terceiros e outras rendas derivadas da aplicação do trabalho familiar.

${ }^{6}$ Renda derivada de transferências de governo.

${ }^{7}$ Total de trabalho familiar e de terceiros aplicado na produção rural.

${ }^{8} 0$ item anterior acrescido do trabalho fora do estabelecimento.

${ }^{9} \mathrm{O}$ item III dividido por III.1 multiplicado por 300 .

${ }^{10} \mathrm{O}$ item III dividido por III.2 multiplicado por 300 .

Por seu turno, a rentabilidade da produção rural por trabalhador-equivalente, que é em média superior à rentabilidade média global por trabalhador-equivalente, cai também no período, passando de $R \$ 5.152,43$ para $R \$ 4.775,00$. Também nesse caso a queda foi maior entre as famílias que não adotaram as técnicas de mulch. A rigor, entre as outras se verifica uma elevação sistemática, de R\$ 3.698,25 em 2000 para $\mathrm{R} \$ 3.832,75$ e, finalmente, para $\mathrm{R} \$ 3.995,60$ (cf. Gráfico 8). 
Que papel desempenharam nessa performance as técnicas de mulch? Para responder a essa pergunta, isolamos os plantios para os quais se adotaram as técnicas de mulch dos outros e calculamos para cada um e seu somatório a renda bruta e a renda líquida, o montante de terra e de trabalho aplicados. De posse disso, calculamos a rentabilidade da terra $\left(p_{a}^{*}\right)$, a rentabilidade do trabalho $\left(R_{a}^{*}\right)$ e a relação terra/trabaIho $\left(a_{a}{ }^{*}\right)$ (ver Tabela 6).

Adotamos, concomitantemente, o mesmo procedimento para os plantios das mesmas culturas que foram testadas com as novas técnicas, em plantios sem as técnicas de trituração, sejam eles conduzidos por famílias que não adotaram de nenhum modo a trituração, ou por famílias que trituraram plantio da mesma ou de outras culturas. Obteve-se com isso a rentabilidade da terra $\left(p_{a}\right)$, a rentabilidade do trabalho $\left(R_{a}\right)$ e a relação terra/trabalho $\left(a_{a}\right)$, desmembradas conforme a posição do plantio em relação ao teste (resultados distribuídos respectivamente na Tabela 7).

A confrontação dos resultados da Tabela 6 com os da Tabela 7 permite verificar a condição de path-efficience para a validação das novas técnicas. A conclusão é que a técnica de trituração, nos níveis de custo vigentes no momento da pesquisa, não se mostrou superior às concorrentes em termos de rentabilidade por unidade de trabalho. $\mathrm{Na}$ verdade, numa comparação dos valores a preços constantes (descontada a inflação), a trituração apresentou rendimentos negativos em todos os anos, para valores respectivos positivos das técnicas concorrentes. Uma observação, contudo, faz-se necessária: enquanto os primeiros tenderam a crescer (valores negativos decrescentes), os últimos decresceram $\mathrm{R} \$-1.813,00$ e $\mathrm{R} \$ 5.754,00, \mathrm{R} \$-1.247,00$ e $\mathrm{R} \$ 3.407,00, \mathrm{R} \$-445,00 \mathrm{e}$ $\mathrm{R} \$ 2.392,00$ para os anos de 2000, 2001 e 2002, respectivamente (cf. Gráfico 9).

A rentabilidade por unidade de área segue movimento semelhante: $R \$-698,00$ e $R \$ 3.875,00, R \$-216,00$ e $R \$ 1.597,00, R \$-86,00$ e $R \$$ $1.137,00$ para os anos de 2000, 2001 e 2002, respectivamente (cf. Gráfico 10).

Haveria tendência nesses movimentos, de modo que se poderia dizer que há uma convergência dos dois valores? Isso, em princípio, iria ao encontro do pensamento dos pesquisadores e tecnólogos, para os quais uma das vantagens da técnica de mulch é a melhoria geral do solo, com o tempo. Impossível, porém, responder conclusivamente com apenas três anos de observação. 
Quanto à relação trabalho/terra, ela se apresenta bem mais elevada e parece inclinada a crescer fortemente entre os que utilizaram a técnica de mulch: 2,6 ha/trabalhador em 2000, passando para 5,77 e 5,18 ha/ trabalhador nos dois anos seguintes. Para os que não utilizaram a trituração, esses valores foram, respectivamente, 1,48, 2,13 e 2,1. As técnicas de trituração, tal como têm sido propostas, parecem tornar 0 uso da terra mais extensivo que suas concorrentes (cf. Gráfico 11).

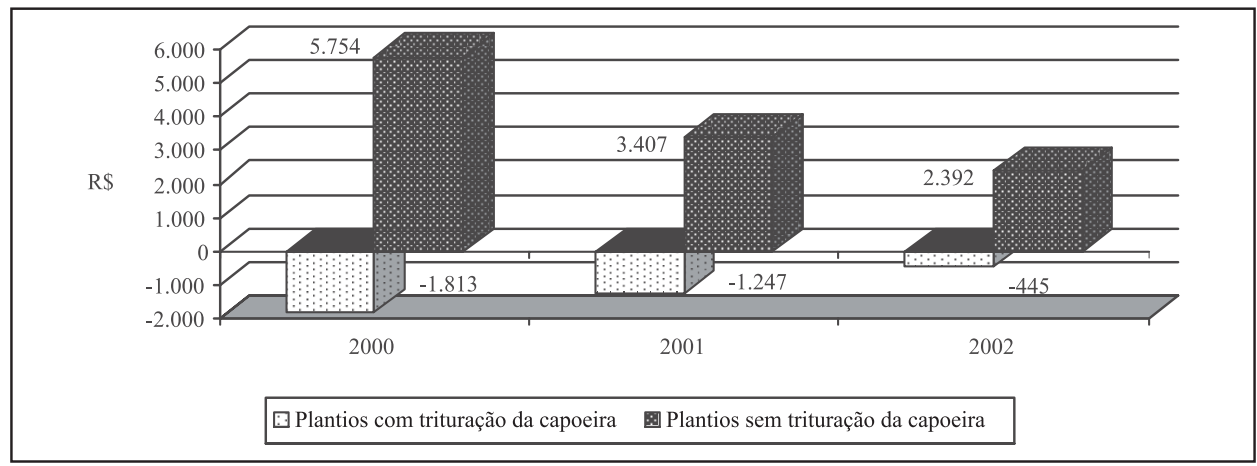

Gráfico 9: Renda líquida por trabalhador equivalente dos plantios com e sem trituração da capoeira, culturas monitoradas para comparação ${ }^{1}$, 2000 a 2002, a preços constantes ${ }^{2}$ em R\$ de 2002.

Fonte: Tabela 6 e Tabela 7.

${ }^{1}$ Maracujá, arroz, feijão, macaxeira, mandioca, milho e pimenta-doce.

${ }^{2}$ Atualização dos preços para 2002 feita pelo IGP/FGV.

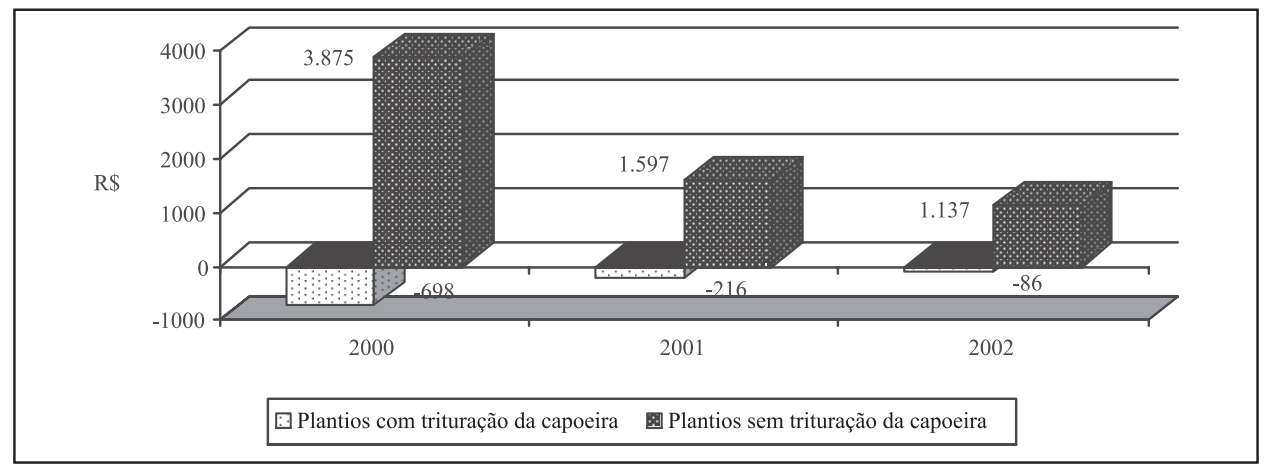

Gráfico 10: Renda líquida por unidade de área (ha) dos plantios com e sem trituração da capoeira, culturas monitoradas para comparação ${ }^{1}, 2000$ a 2002, a preços constantes ${ }^{2}$ em R $\$$ de 2002.

Fonte: Tabela 6 e Tabela 7.

${ }^{1}$ Maracujá, arroz, feijão, macaxeira, mandioca, milho e pimenta-doce.

${ }^{2}$ Atualização dos preços para 2002 feita pelo IGP/FGV. 


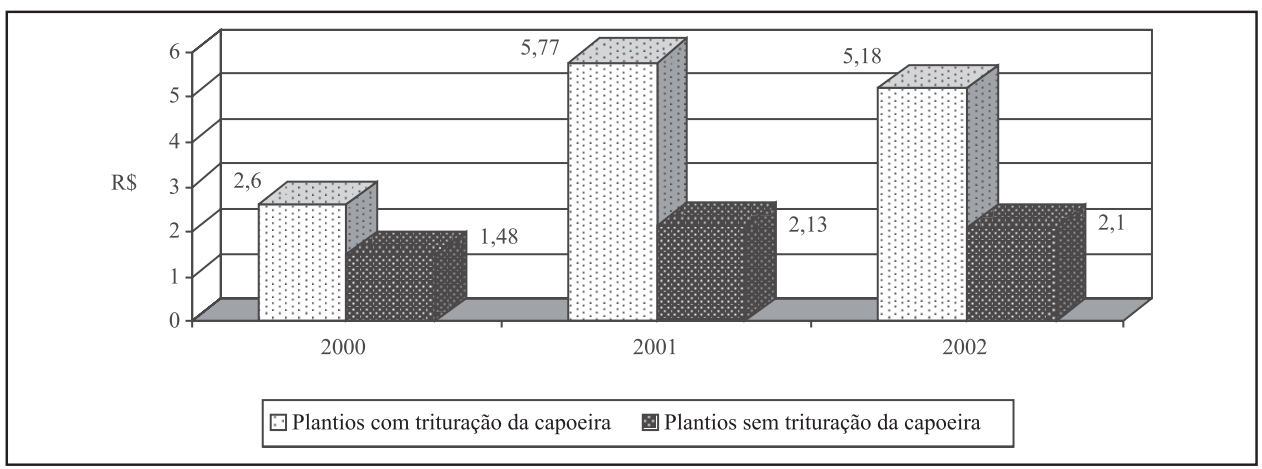

Gráfico 11: Relação terra/trabalho (hectares/trabalhador equivalente), culturas monitoradas para comparação ${ }^{1}$.

Fonte: Tabela 6 e Tabela 7.

1 Maracujá, arroz, feijão, macaxeira, mandioca, milho e pimenta-doce.

Tabela 6: Rentabilidade por trabalhador equivalente, rentabilidade por unidade de área e relação terra/trabalho dos plantios que utilizaram a trituração da capoeira (R\$ preços correntes).

\begin{tabular}{|c|c|c|c|}
\hline & 2000 & 2001 & 2002 \\
\hline I. Renda bruta dos plantios ${ }^{1}$ & 0,00 & $4.528,90$ & $1.171,50$ \\
\hline (-) Custo com fertilizantes e inseticidas ${ }^{2}$ & 0,00 & 373,50 & 0,00 \\
\hline (-) Custo com trabalho de terceiros ${ }^{3}$ & 0,00 & $1.231,26$ & 46,42 \\
\hline (-) Custo com mecanização ${ }^{4}$ & 301,50 & $4.443,70$ & $1.358,70$ \\
\hline II. Renda líquida dos plantios & $-301,50$ & $-1.519,56$ & $-233,62$ \\
\hline II.1.Terra aplicada (ha) $)^{5}$ & 0,60 & 8,89 & 2,72 \\
\hline II.2. Trabalho aplicado $(\mathrm{D} / \mathrm{H})^{6}$ & 69,61 & 462,28 & 157,50 \\
\hline III. Renda líquida por hectare ${ }^{7}\left(\mathrm{p}_{a}{ }^{*}\right)$ & $-500,00$ & $-170,98$ & $-85,97$ \\
\hline IV. Área plantada/trabalhador equivalente ${ }^{8}\left(\mathrm{a}_{\mathrm{a}}{ }^{*}\right)$ & 2,60 & 5,77 & 5,18 \\
\hline V. Renda líquida por trabalhador equivalente ${ }^{9}\left(\mathrm{R}_{\mathrm{a}}{ }^{*}=\mathrm{p}_{\mathrm{a}}{ }^{*}\right.$ & $-1.299,33$ & $-986,13$ & $-444,99$ \\
\hline
\end{tabular}

Fonte: Pesquisa de campo, Projeto ENV-44, NAEA.

Notas:

${ }^{1}$ Soma de toda a produção rural ao preço de cada transação. Para a produção não vendida (autoconsumo), utilizou-se o preço médio do produto para todo o grupo. As culturas monitoradas foram: maracujá, arroz, feijão, macaxeira, mandioca, milho e pimenta-doce.

${ }^{2}$ Incluiu todas as formas de fertilizantes e inseticidas adquiridos no mercado.

${ }^{3}$ Todas as formas de trabalho remunerado de terceiros.

${ }^{4}$ Custo de aplicação dos equipamentos para a trituração da capoeira a $\mathrm{R} \$$ 500.

${ }_{6}^{5}$ Área aplicada no plantio.

${ }^{6}$ Total de trabalho familiar e de terceiros aplicado na produção.

${ }^{7} \mathrm{O}$ item II dividido por II.1. 
Tabela 7: Rentabilidade por trabalhador equivalente, rentabilidade por unidade de área e relação terra/trabalho dos plantios das mesmas culturas que foram testadas com trituração em estabelecimentos que não utilizaram a trituração da capoeira (R\$ preços correntes).

\begin{tabular}{|c|c|c|c|}
\hline & 2000 & 2001 & 2002 \\
\hline I. Renda bruta dos plantios 1 & $111.358,63$ & $89.583,82$ & $65.474,33$ \\
\hline (-) Custo com fertilizantes e inseticidas & $5.301,75$ & $10.266,75$ & $3.312,25$ \\
\hline (-) Custo com trabalho de terceiros 3 & $8.860,68$ & $9.300,37$ & $3.901,18$ \\
\hline (-) Gusto com mecanização & - & 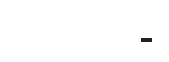 & - \\
\hline II. Renda líquida dos plantios & $97.196,20$ & $70.016,70$ & $58.260,90$ \\
\hline II.1. Terra aplicada (ha) ${ }^{5}$ & 35,00 & 55,41 & 51,25 \\
\hline II.2. Trabalho aplicado (D/H) & $7.072,42$ & $7.793,92$ & $7.307,50$ \\
\hline III. Renda líquida por hectare ${ }^{7}\left(\mathrm{p}_{\mathrm{a}}{ }^{*}\right)$ & $2.776,98$ & $1.263,50$ & $1.136,85$ \\
\hline IV. Área plantada/trabalhador equivalente ${ }^{8}\left(\mathrm{a}_{\mathrm{a}^{*}}\right)$ & 1,48 & 2,13 & 2,10 \\
\hline $\begin{array}{l}\text { V. Renda líquida por trabalhador equivalente }\left(\mathrm{R}_{\mathrm{a}}^{*}=\right. \\
\left.\mathrm{p}_{\mathrm{a}}^{*} \cdot \mathrm{a}_{\mathrm{a}}^{*}\right)\end{array}$ & $4.122,90$ & $2.695,05$ & $2.391,83$ \\
\hline
\end{tabular}

Fonte: Pesquisa de campo, Projeto ENV-44, NAEA.

Notas:

${ }^{1}$ Soma de toda a produção rural ao preço de cada transação. Para a produção não vendida (autoconsumo), utilizou-se o preço médio do produto para todo o grupo. maracujá, arroz, feijão, macaxeira, mandioca, milho e pimenta-doce.

2 Incluiu todas as formas de fertilizantes e inseticidas adquiridos no mercado.

${ }^{3}$ Todas as formas de trabalho remunerado de terceiros.

${ }^{4}$ Custo de aplicação dos equipamentos para a trituração da capoeira a R\$ 500.

${ }_{6}^{5}$ Área aplicada no plantio.

${ }^{6}$ Total de trabalho familiar e de terceiros aplicado na produção.

${ }^{7} \mathrm{O}$ item II dividido por II.1.

${ }^{10} \mathrm{O}$ item II dividido por II.2 multiplicado por 300 . 


\section{CONCLUSÕES}

As capoeiras são componentes da paisagem rural de grande significado na realidade agrária da Amazônia, cobrindo 4,5 milhões de hectares em 1995, quando da realização do último Censo Agropecuário.

No bojo das discussões sobre sustentabilidade econômica e ecológica da agricultura na Amazônia, Chomitz e Hurtienne (2000) e Schneider, Arima, Veríssimo, Barreto e Souza J r. (2000) sustentam diretamente que a parcela desse valor correspondente à variável Terras úteis não utilizadas, do Censo Agropecuário do IBGE, é precisamente o que indica a semântica da designação: terras sem função, terras abandonadas, por isso indicadores de sistemas de produção econômica e ecologicamente insustentáveis. Essas terras somavam na Região Norte, no ano do Censo, 3,4 milhões de hectares, representando $76 \%$ de todas as capoeiras e $6 \%$ do total das terras apropriadas. Com tal indicação de fracasso da agricultura, em qualquer forma, essa perspectiva aponta para um dramático lock-in em favor da pecuária na Amazônia (MARGULIS, 2003, p. 65).

Tal posição carece de sustentação. Demonstrou-se acima que $42 \%$ das Terras úteis não utilizadas do IBGE estão associadas a mudanças nos sistemas produtivos, baseadas na intensificação do uso do solo pela introdução de culturas permanentes. São áreas que resultam, pois, de inovações numa trajetória ascendente e não descendente da evolução da agricultura. Nessa trajetória, a shifting cultivation constitui um estágio que, no momento seguinte, é superado por sistemas baseados em culturas permanentes, formando capoeiras-reserva: sem tempo para reutilização, passível de vir a reconstituir todas as funções da floresta primária. É um fenômeno observado em toda a Região Norte. Mesmo na mesorregião Nordeste Paraense, apresentada como paradigmática do fracasso da agricultura por causa do montante de suas capoeiras, as capoeiras-reserva somavam, em 1995, próximo de 184 mil hectares $38 \%$ do total da variável censitária em discussão -, por força da produtividade das culturas permanentes 1,7 vezes superior à das culturas temporárias., Detectamos uma produtividade física superior impulsionando a passagem, ao par de uma produtividade monetária tendencialmente crescente dos sistemas baseados em culturas permanentes comparativamente às culturas da shifting cultivation em quase todo o período que vai de 1990 a 2003. De modo que, nos oito anos observados, produziu-se um montante adicional de 300.000 hectares de capoeiras-reserva. 
O contraponto estrutural das copoeiras-reserva são as capoeirassucata - detectadas nos estabelecimentos em que há capoeiras e pecuária, na proporção do significado dessa última no sistema de produção. Esse tipo de capoeira somava 2,3 milhões de hectares no ano de Censo. Uma pecuária de corte que concilia uso extensivo da terra com rendimentos crescentes de escala - rendimentos baixos e constantes da terra, aliados a rendimentos do trabalho crescentes com a escala de produção, isto é, com o tamanho do rebanho - tem se expandido fortemente na Região, garantindo as mesmas condições verificadas no ano do Censo no que se refere à formação de capoeiras-sucata. Assim, no período referido, 2,2 milhões de hectares adicionais desse tipo de capoeira devem ter se formado: uma vegetação que, deixada ao seu próprio ritmo, requer muito tempo para reconstituir as funções da floresta; ou cuja regeneração imediata exige investimentos elevados.

As capoeiras-capital, aquelas que se encontram em função na shifting cultivation, constituíam o item de menor peso na contabilidade das capoeiras no ano do Censo: 771,6 mil hectares. Trata-se, também, do tipo de capoeira que menos cresceu no período discutido: 62,7 mil hectares. Todavia, considerando a possibilidade de que, mediante crises institucionais (menos terra que o necessário) ou de mercado (relações de preços desfavoráveis) dos sistemas que pressupõem esse tipo de capoeira, podem surgir capoeiras-sucata, esforços institucionais têm sido feitos para tornar as capoeiras-capital mais eficientes e os sistemas de que fazem parte menos vulneráveis. As pesquisas voltadas para a mecanização da shifting cultivation, como as empreendidas no contexto do projeto SHIFT-Capoeira, representam formas de manutenção das capoeiras-capital por manejo alternativo às formas tradicionais de uso das áreas de pousio. Partindo do pressuposto de que as possibilidades desses procedimentos tecnológicos dependem do impacto que produzem sobre o payoff dos agentes em comparação com as tecnologias alternativas, empreendemos cálculos que fazem esse confronto com base em três variáveis fundamentais: a rentabilidade do trabal ho aplicado, a rentabilidade da terra e a relação terra/trabalho.

Para todas essas variáveis, as técnicas de trituração testadas mostraram-se inferiores às técnicas concorrentes: a rentabilidade da terra e do trabalho foi negativa, em relação aos valores positivos dos 
plantios que adotaram as técnicas tradicionais em todos os três anos estudos. A relação terra/trabalho mostrou-se maior e crescente comparativamente às de outras técnicas. De modo que, avaliada por essa ótica - a que vige nas condições econômicas e institucionais presentes - , as inovações propostas terão dificuldades de incorporação produtiva, visto que não se mostram path-efficient. Isso pode mudar, contudo, se desenvolvimentos institucionais se fizeram também no sentido de garantir, para os produtores, os ganhos ambientais delas derivados, em particular os derivados do seqüestro de carbono (ver RODRIGUES et al., 2005).

Uma última questão: há risco de lock-in do agrário da Região na pecuária extensiva e altamente formadora de capoeira-sucata? Ou, observando na direção contrária, há possibilidade de lock-in em sistemas baseados em culturas permanentes? Não há, quanto a isso, respostas definitivas. Pode-se adiantar, entretanto, que tudo depende do desfecho da concorrência entre os agentes, em sua diversidade fundamental, tanto no plano do mercado, quanto, sobretudo, na arena institucional - na definição da produção e na internalização de inovações e de configurações normativas quanto aos usos da base natural da região. Uma institucionalidade que vise a sustentabilidade dos usos da base natural da região, valorizando os que não geram e limitando os que geram capoeiras-sucata, constituirá uma referência necessária a um desenvolvimento de novo tipo. A construção de tal possibilidade deverá ser uma preocupação de peso, tanto para os pesquisadores, quanto para os policy makers associados à Amazônia. 


\section{REFERÊNCIAS}

ARTHUR, W. B. Path Dependence, Self-Reinforcement, and Human Learning. In: ARTHUR, W. B. Increasing Returns and Path Dependence in the Economy. Michigan: The University of Michigan Press, 1994a. p. 134-158.

ARTHUR, W. B. Competing Technologies, Increasing Returns, and Lock-In by Historical Small Events. In: ARTHUR, W. B. Increasing Returns and Path Dependence in the Economy. Michigan: The University of Michigan Press, 1994b. p. 13-32.

BRIENZA J UNIOR, S.; VIEIRA, I. C. G.; VIEIRA, I. C. G.; YARED, J . Considerações sobre a recuperação de áreas alteradas por atividades agropecuária e florestal na Amazônia Brasileira. Boletim de Pesquisa EMBRAPA/CPATU, Belém, v. 83, p. 1-27, 1995.

CARVALHO, H. M. 0 campesinato no século XXI: possibilidades e condicionantes do desenvolvimento do campesinato no Brasil. Petrópolis: Vozes, 2005.

CHAYANOV, A. Die Lehre von der bäuerlichen Wirtschaft: Versuch einer Theorie der Familienwirtschaft im Landbau. Berlin: Verlag Paul Parey, 1923.

CHOMITZ, K.; THOMAS, T. S. Geographic Patterns of Land Use and Land Intensity. Washington, D.C.: World Bank, Development Research Group, Draft Paper, 2000.

COSTA, F. A. Amazonien - Bauern, Märkte und Kapitalakkumulation. Saarbrücken. Fort Lauderdale/Saarbrücken: Velag Breitenbach Publishers, 1989.

COSTA, F. A. O investimento camponês: considerações teóricas. Revista de Economia Política, São Paulo, v. 15, n. 1, p. 83-100, 1995.

COSTA, F. A. Agricultura familiar em transformação na Amazônia: o caso de Capitão Poço e suas implicações para a política e o planejamento agrícola regional. Revista Econômica do Nordeste, Local, v. 27, n. 4, p. 633-672, 1996a.

COSTA, F. A. Campesinato abre caminho na Amazônia. Ciência Hoje, Rio de Janeiro, v. 20, n. 120, p.16-23, 1996b. 
COSTA, F. A. Padrões de reprodução e dinâmica de mudança de camponeses na Amazônia: os casos de Capitão Poço e Irituia. Revista Econômica do Nordeste, Local, v. 28, n. 3, p. 27-43, 1997.

COSTA, F. A. A formação agropecuária da Amazônia. Belém: NAEA, 2000.

COSTA, F. A. A relação dos preços na agricultura dos Estados Unidos: uma observação a partir de abordagem baseada em eficiência reprodutiva. In: ENCONTRO NACIONAL DE ECONOMIA POLÍTICA, 7., 2002, Curitiba. Anais... Curitiba: Sociedade Brasileira de Economia Política, 2002.

COSTA, F. A. Questão agrária e macropolíticas para a Amazônia. Estudos Avançados, Local, v. 19, n. 53, p. 131-156, jan./abr. 2005.

COSTA, F. A.; ANDRADE, W. D. C.; FIOCK, F. O processamento de frutas no Nordeste Paraense e Região Metropolitana de Belém: um arranjo produtivo local emergente. Rio de J aneiro, RedeSist/IE-UFRJ . Disponível em: < http:// www.redesist.br>. Acesso em: 15 de maio de 2004.

COSTA, F. de A.; VON BRAUN, J. Projeto CHIFT/CNPQ ENV 44: pequenos produtores na Amazônia: inter-relações entre ecossistema e sistema social na utilização e proteção da floresta tropical. Belém, Bonn: NAEA/ZEF, 2000.

DENICH, M.; VIELHAUER, K.; KATO, M. S. A.; BLOCK, A.; KATO, O. R.; SÁ, T. D. A.; LÜCKE, W.; VLEK, Paul L. G. Mechanized land preparation in forestbased fallow systems: The experience from eastern Amazonia. Agroforestry Systems, Netherlands, v. 61, p. 91-2004, 2004.

FNP. Anuário da Pecuária Brasileira - ANUALPEC 2003. São Paulo: FNP, 2003.

FNP. Anuário da Pecuária Brasileira - ANUALPEC 2004. São Paulo: FNP, 2004.

FREITAS, A. C. R. Crise ecológica e mudança técnica da agricultura camponesa de derruba e queima da Amazốnia Oriental. 2004.Tese (Doutorado em Desenvolvimento Sustentável do Trópico Úmido) - Núcleo de Altos Estudos Amazônicos, Universidade Federal do Pará, Belém, 2004.

HEINER, R. Imperfect decision and routinized production: implications for evolutionary modelling and inertial technical change. In: DOSI, G.; FREEMAN, C.; NELSON, R.; SILVERBERG, G.; SOETE, L. (Ed.). Technical Change and Economic Theory. London and New York: Pinter Publisher, 1988. 
HURTIENNE, T. P. Ecologia tropical, agricultura familiar e desenvolvimento rural sustentável. Ciência e Ambiente, Santa Maria, RS, n. 15, p. 79-92, 1998.

HURTIENNE, T. P. Agricultura familiar e desenvolvimento rural sustentável na Amazônia. In: COELHO, Maria Célia Nunes (Org.). Estado e políticas públicas na Amazônia: gestão do desenvolvimento regional. Belém: Cejup, 2001. p. 177-283.

KATO, M. S. A.; KATO, O. R.; DENICH, M.; VLEK, P. L. G. Fire-free alternatives to slash-and-burn for shifting cultivation in the eastern Amazon region: the role of fertilizers. Field Crop Research, Amsterdam, v. 62, p. 225-237, 1999.

KATO, M. S. A.; SÁ, T. D. A.; KATO, O. R.; BREINZA J UNIOR, S. Tecnologia alternativas para uso na agricultura familiar. Agir Percepção da Gestão Ambiental, São Paulo, v. 5, p. 205-208, 2004a.

KATO, O. R.; KATO, M. S. A.; SÁ, T. D. A.; FIGUEIREDO, R. O. Plantio direto na capoeira. Ciência e Ambiente, Santa Maria, RS, v. 29, p. 99-111, 2004b.

KRUG, T. O quadro do desflorestamento da Amazônia. In: BRASIL. Ministério do Meio Ambiente. Causas e dinâmica do desmatamento na Amazônia. Brasília, 2001. p. 91-98.

LICHA, A. L. Racionalidade num ambiente não ergódico. In: ENCONTRO NACIONAL DE ECONOMIA, 24., 1996, Local. Anais... Local: ANPEC, dez. 1996. p. 494-514.

LICHA, A. L. Racionalidade e coordenação num ambiente de incerteza. Econômica, Local, n. 3, p. 103-117, 2000.

MARGULIS, S. Causas do desmatamento da Amazônia Brasileira. Brasília, DF: Banco Mundial, 2003.

MARX, K. Grundrisse der Kritik der Politischen Ôekonomie: Rohenentwurf. Berlin: Dietz Verlag, 1953.

PEREIRA, C. A.; VIEIRA, I. C. G. A importância das florestas secundárias e os impactos de substituição por plantios mecanizados de grão na Amazônia. Interciência, Local, v. 26, p. 337-341, 2001. 
PONTE, M. X.; VAN DYNE, D. L. Sistemas agroindustriais integrados: uma análise por meio da entropia de informação. Novos Cadernos do NAEA, Belém, v. 3, n. 1, p. 47-62, jun. 2000.

RODRIGUES, G. S.; KITAMURA, P. C.; SÁ, T. D. de A.; VIELHAUER, K. Avaliação da sustentabilidade das formas de manejo da agricultura itinerante com ou sem queima da capoeira no Nordeste do Pará. 2005. Manuscrito.

SÁ, T. D. A.; KATO, M. S. A.; KATO, O. R. A dominância das capoeiras na paisagem agrícola da Amazônia. Ver Percepção do Diagnóstico Ambiental, São Paulo, v. 3, p. 109-113, 2004.

SCHNEIDER, R. R. Government and the Economy on the Amazon Frontier. Washingtaon: The World Bank, 1995.

SCHNEIDER, R. R.; ARIMA, E.; VERÍSSIMO, A.; BARRETO, P.; SOUZA J R., C. Amazônia sustentável: limitantes e oportunidades para o desenvolvimento rural. Brasília/Belém: Banco Mundial/IMAZON, 2000.

TEPICHT, J. Marxisme et agriculture: le paysan polonais. Paris: Armand Colin, 1973.

VIEIRA, I. C. G.; VIEIRA, I. G.; SALOMÃO, R. P.; NEPSTAD, D. C.; ROMA, J .; ROSA, N. O. Renascimento da floresta no rastro da agricultura. Ciência Hoje, Rio de Janeiro, v. 20, n. 119, p. 38-44, 1996.

VIELHAUER, K.; KANASHIRO, M.; SÁ, T. D. A. Fallow Vegetation and Secondary Forest (Capoeira) in the Agric. Landscape of Ent. - Amaz.: Function and Management. Germany Brazil Coop in Env. Res. and Tech .News Latter, Göttingen, v. abril, p. 2-3, 1997. 